Marino Silvia (Orcid ID: 0000-0003-3695-0908)

\title{
Therapeutic targets in myeloma bone disease
}

\author{
Silvia Marino ${ }^{1} \mathrm{MSc}, \mathrm{PhD}$ \\ Daniela N Petrusca ${ }^{1}, \mathrm{MSc}, \mathrm{PhD}$ \\ G. David Roodman ${ }^{1,2} \mathrm{MD}, \mathrm{PhD}$
}

1. Department of Medicine, Division Hematology Oncology, Indiana University School of Medicine, 980 W. Walnut Street, Indianapolis, Indiana, USA 46202

2. Roudebush VA Medical Center Indianapolis, IN, USA, 46202.

\section{Correspondence to:}

Silvia Marino MSc. PhD

IU School of Medicine

Division of Hematology/Oncology

$980 \mathrm{~W}$. Walnut

Room C340

Indianapolis, IN 46202

Tel: +1 (317) 689-9624

Email: simarino@iu.edu

Running title: Targeting myeloma bone disease

\begin{abstract}
Abbreviation: BM, bone marrow; BMSCs, bone marrow stromal cells; CCR1, C-C chemokine receptor type 1; Dkk-1 dickkopf-1; ICAM-1, intercellular adhesion molecule 1; IGF-1, insulin-like growth factor 1; IL, interleukin; IMiDs, immunomodulatory drugs; G$\mathrm{CSF}$, granulocyte colony stimulating factor; GM-CSF, granulocyte-macrophage colonystimulating factor; Gfi-1, transcriptional repressor growth factor independent 1; M-CSF, macrophage colony-stimulating factor; MGUS, monoclonal gammopathy of undetermined significance; MIP-1 $\alpha$, macrophages inflammatory protein-1 $\alpha$; miRNAs, micro RNAs; MM,
\end{abstract}

This is the author's manuscript of the article published in final edited form as:

Marino, S., Petrusca, D. N., \& Roodman, G. D. (2019). Therapeutic targets in myeloma bone disease. British Journal of Pharmacology, n/a(n/a). https://doi.org/10.1111/bph.14889 
multiple myeloma: MBD, MM bone disease; MMP, matrix metalloproteinase; NK, natural killer cells; OAF, osteoclast-activating factors; OB, osteoblast; OC, osteoclast; OCY, osteocyte: RANKL, receptor activator of nuclear factor- $\kappa \mathrm{B}$ ligand; SDF-1, stromal-derived growth factor-1; TGF- $\beta$, Transforming growth factor $\beta$; TNF- $\alpha$, tumor necrosis factor $\alpha$; VCAM, vascular cell adhesion molecule; VEGF, vascular endothelial growth factors;

\section{Abstract}

Multiple myeloma (MM) is the second-most-common hematologic malignancy and is characterized by a clonal proliferation of neoplastic plasma cells within the bone marrow. $\mathrm{MM}$ is the most frequent cancer involving the skeleton, causing osteolytic lesions, bone pain, and pathological fractures that dramatically decrease MM patients' quality of life and survival. MM bone disease (MBD) results from uncoupling of bone remodelling in which excessive bone resorption is not compensated by new bone formation, due to a persistent suppression of osteoblast activity. Current management of MBD includes anti-resorptive agents i.e. bisphosphonates and denosumab that are only partially effective due to their inability to repair the existing lesions. Thus, research into agents that prevent bone destruction and more importantly repair existing lesions by inducing new bone formation, is of the utmost importance. This review discusses the mechanisms regulating the uncoupled bone remodelling in MM, and summarizes current advances in the treatment of MBD.

\section{Bullet point summary -}

'What is already known',

1. MM is still incurable and $80 \%$ of patients develop lytic bone disease.

2. The majority of lytic lesions do not repair even when the patients are in complete remission.

'What this study adds'

1. We review and summarize recent advances in the pathogenesis of MBD.

2. Provide possible new mechanism(s) that can be targeted to build bone.

'Clinical significance'.

1. Current MBD treatments are only anti-resorptive and not anabolic.

2. Provides support for potential safe anabolic agents that actively stimulate bone formation.

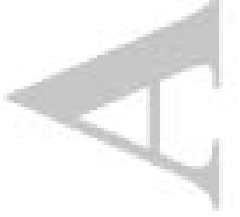




\section{Introduction}

Multiple myeloma (MM) is the second most common hematological malignancy that results from an uncontrolled clonal proliferation of malignant plasma cells, in the bone marrow microenvironment. It is characterized by the production and accumulation of paraproteins (monoclonal immunoglobulins) detectable in patient's blood and urine. Approximately 32,110 new cases will be diagnosed in the United States in 2019 with 12,960 deaths due to MM (Siegel, Miller \& Jemal, 2019). The incidence of MM is 2-3 times higher in African Americans than in Caucasians. The overall 5-year survival rate is $50 \%$. Clinically, MM is a debilitating disease characterized by bone destruction (> $80 \%$ of patients), hypercalcemia (30\% of patients), acute renal failure (20\% of patients), anemia (60\% of patients) and reductions in normal gamma globulins (immunoparesis).

Despite the fact that survival rates have greatly improved in recent years, $M M$ is incurable in the majority of patients since more than $80 \%$ of patients develop bone diseases (MBD) over the course of their disease (Roodman, 2010). MBD represents a major issue in the current management of MM. Skeletal involvement is responsible for some of the most devastating complications associated with MM, including pathological fractures that can occur in 50-60\%

of patients, causing debilitating pain and spinal cord compression syndromes which reduce quality of life and increase mortality risk by up to $20 \%$ (Saad, Lipton, Cook, Chen, Smith \& Coleman, 2007).

MBD is caused by interactions between myeloma and cells of the bone microenvironment, that result in the formation of lytic bone lesions and generalized bone loss. These interactions lead to a profound deregulation of the normal bone remodeling process with excessive osteoclastic bone resorption accompanied by a substantial suppression of osteoblastic bone formation, thus results in little or no new bone deposition (Roodman, 2009). Moreover, the majority of lytic lesions do not repair and persist even when the patients are in complete remission and with no evidence of marrow infiltration by MM cells, due to the severe and persistent suppression of osteoblast (OB) activity that characterizes MM (Roodman, 2011) (Fig1).

Current treatments for MBD such as bisphosphonates and denosumab are only anti-resorptive and reduce further bone destruction by osteoclasts but do not actively stimulate bone formation. Recently, several bone anabolic agents have been tested in preclinical models of MBD and studies to develop novel safe anabolic agents for MBD are ongoing. This review discusses current and novel therapeutic approaches that target MBD. 


\section{Pathophysiology of Myeloma Bone Disease}

The normal physiologic bone remodeling that regulates the balance between osteoclast (OC) and $\mathrm{OB}$ activity is uncoupled in MBD. The bone marrow microenvironment consists of a cellular compartment and a mineralized extracellular matrix. Marrow cells and components of the marrow microenvironment including OCs, OBs, osteocytes (OCYs), immune cells and stromal cells, produce membrane-bound and soluble growth factors, that stimulate the homing, growth, proliferation and drug-resistance of MM cells (Andrews, Kabrah, May, Donaldson \& Morse, 2013). MM in turn stimulate OC formation directly or by physically interacting with stromal cells and $\mathrm{OBs}$, to produce factors that drive $\mathrm{OC}$ formation and suppress OB activity, thereby creating a "vicious cycle" that increases bone resorption and tumor burden (Marino \& Roodman, 2017). Conversely, OB function is extremely suppressed or absent, resulting in purely lytic bone lesions that rarely repair. Immobilized matrix-derived growth factors, such as transforming growth factor $\beta$ (TGF- $\beta$ ), are released from the resorbed bone matrix, further promoting MM cell growth.

The physiological state of the microenvironment is a key element in the tumor progression as it can be both tumor-promoting or tumor-restricting. The highly vascularized metaphysis of the bone is the preferential site of MM engraftment and the perivascular niche has been shown to regulate MM cell homing and dissemination (Ribatti, Basile, Ruggieri \& Vacca, 2014). The uncontrolled growth of disorganized new MM-associated vessels supports MM cell growth and chemoresistance (Moschetta et al., 2016). Finally, the hypoxic microenvironment further activates vasculogenesis (Storti et al., 2013) and enhance the genomic instability of MM cells, selecting for dormant MM cell clones thus contributing to MM drug resistance (Hu, Van Valckenborgh, Menu, De Bruyne \& Vanderkerken, 2012)

The tumor-immune interactions in MM are distinct since MM cells are themselves immune cells (plasma cells) and localise primarily in the bone marrow (BM), a specialized tissue for survival of immune cells. Here they interact with bone cells, suggesting a potential role for these interactions in regulating both tumor progression and tumor immunity. The immunosuppressive environment that is associated with MM, contributes to the immune escape of the MM cells because of their inadequate antigen presentation (Hideshima, Mitsiades, Tonon, Richardson \& Anderson, 2007), indicating that enhancing immune surveillance may play a role in the prevention of MM disease progression.

Furthermore, recent studies showed interplay between MM cells and marrow adipocytes, actively support the proliferation and migration of MM cells, protect MM cells from chemotherapy-induced apoptosis and disrupt haematopoiesis, leading to the disruption of 
immune function and contribute to myeloma-induced bone disease (Trotter, Gibson, Sherpa, Gowda, Peker \& Yang, 2016) (Liu et al., 2019) (Fig 2).

\section{Cellular components of myeloma bone disease}

\section{Bone marrow stromal cells}

Bone marrow stromal cells (BMSCs) are a special class of multi-potent cells that represent a common progenitor for OBs, OCYs, adipocytes, chondrocytes, muscle cells and most of the stromal cells in the bone marrow (Lindner, Kramer, Rohwedel \& Schlenke, 2010). BMSCs function is highly influenced by the surrounding microenvironment, and thus, it is altered in MM and contributes to multiple stages of the pathophysiology of MBD (Olechnowicz \& Edwards, 2014). The capability of MM-BMSCs to differentiate into functional OBs is severely compromised although is still unclear whether these modifications are permanent or require the presence of MM cells (Kassen et al., 2014). MM-BMSCs express a distinct genomic profile when compared to healthy-BMSCs (Munshi \& Avet-Loiseau, 2011). BMSCs isolated from MM patients secrete high level of tumor promoting and anti-apoptotic factors, such as interleukin (IL) IL-6 (Harding et al., 2018), insulin-like growth factor 1 (IGF-1), vascular endothelial growth factors ( $\underline{\mathrm{VEGF}})$, tumor necrosis factor $\alpha(\underline{\mathrm{TNF}}-\alpha)$, stromalderived growth factor-1 $\alpha(\underline{\mathrm{SDF}-1})$ and express higher level of adhesive molecules intercellular adhesion molecule 1 ( $\underline{\text { ICAM-1) }}$ ) and vascular cell adhesion molecule 1 (VCAM1), which contribute to drug resistance in MM. Moreover, adhesive interactions between MM cells and BMSCs are responsible for the production of BMSCs-derived receptor activator of

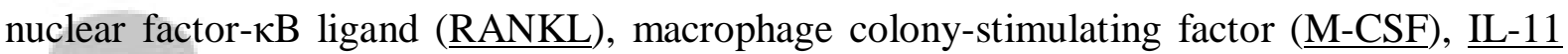
and IL-6 and MM-derived macrophages inflammatory protein-1 $\alpha$ (MIP-1 $\alpha)$ IL-3 and VEGF that regulate osteoclastogenesis (reviewed in (Marino \& Roodman, 2017)). In addition, MMBMSCs also produce exosomes containing proteins, DNA and microRNAs that can prime the bone microenvironment to promote MM dissemination and support MM growth (Guo et al., 2017).

Over the past years there has been great interest in understanding epigenetic and transcriptional signatures changes that MM cells induce on BMSCs (reviewed in (Adamik, Galson \& Roodman, 2018). We recently showed that epigenetic-based mechanisms are involved, at least in part, in the persistence osteogenic suppression of MM-BMSCs (Adamik et al., 2017; D'Souza et al., 2011). We found that upregulation and enhanced binding of the Runx2-transcriptional repressor growth factor independent 1 (Gfi-1) to the Gfi-1-response element within the Runx 2 promoter mediated the sustained suppression of osteogenesis. In 
MM-exposed BMSC cells, Gfi-1 acted as a platform for the formation of a repressive complex containing enhancer of zeste homolog 2 (EZH2), histone deacetylase 1 (HDAC1) and lysine-specific demethylase 1 (LSD1). Moreover, Gfi-1 can regulates adipogenesis, suggesting that Gfi-1 may both suppress and shift the differentiation of MM-exposed BMSCs towards adipogenesis (Wang et al., 2016). We showed that blockade of the p62-ZZ-domain of p62, a signalling platform that mediates the inflammatory response in BMSC exposed to MM cells, with a novel small molecule inhibitor XRK3F2, resulted in inhibition of Gfi-1 activity and rescued osteogenesis of MM-exposed BMSCs (Adamik et al., 2018). XRK3F2 prevented deacetylation of the Runx2 promoter and alleviated MM-suppressed osteogenesis in vitro (Adamik et al., 2018) as well as in vivo (Teramachi et al., 2016). These results suggest that targeting p62 may allow restoration of OB function in patients with MBD. The role of pharmacological treatments that target epigenetic mechanisms suppressing OB differentiation of MM-BMSCs are under investigation (previously reviewed by (GarciaGomez, Sanchez-Guijo, Del Canizo, San Miguel \& Garayoa, 2014).

\section{Osteoblasts}

MBD is characterized by a severe suppression of OBs activity, which results in generalized bone loss due to the inability of the OBs to repair the lesions caused by the excessive osteoclastic resorption (Roodman, 2011). Both soluble factors and physical interaction between MM cells and $\mathrm{OB}$ progenitors inhibit $\mathrm{OB}$ differentiation and increase apoptosis in OBs (Giuliani \& Rizzoli, 2007).

As noted above, we and others showed that the suppression of the activity and function of Runx2 expressed in both mesenchymal and osteoprogenitor cells by MM cells, is principally mediated by direct cell-cell interaction, although soluble factors released by MM cells and cells in the bone microenvironment also contribute to Runx2 suppression (D'Souza et al., 2011; Giuliani et al., 2005). Further, inhibition of Runx2 reduces osteoprotegerin (OPG) (Nelson et al.) secretion resulting in increased osteoclastogenesis. Soluble factors including TGF- $\beta$, released by the bone matrix after OC resorption, inhibits OB differentiation (Matsumoto \& Abe, 2011). IL-7 also suppresses OB differentiation, prevents bone formation and induces bone loss in animal model of MM. Neutralizing antibodies directed against IL-7, partially reduce MM-down-regulation of Runx2 transcriptional activity and OB suppression (Giuliani et al., 2005).

MM cells also induce high level of TNF- $\alpha$ in the MM-bone marrow microenvironment. TNF$\alpha$ is known to play a dual role as it increases osteoclastogenesis and inhibits OB differentiation by decreasing Runx2, Osterix, type-1 collagen, osteocalcin, and matrix 
deposition and induces apoptosis of mature OBs (Ghali, Chauveau, Hardouin, Broux \& Devedjian, 2010). Recently, we showed that IL-7 and TNF- $\alpha$ also induce Gfi-1, potentiating OB suppression (D'Souza et al., 2011).

IL-3, has also been shown to play a dual role in MBD. It significantly increases OC activity, prevents $\mathrm{OB}$ differentiation and inhibits mineralization of mature OBs via inducing Activin A, a TGF- $\beta$ cytokine member (Vallet et al., 2010).

The Wnt signalling pathway is an essential regulator of OB proliferation, differentiation and survival. Dkk-1 is an extracellular antagonist of the Wnt pathway that prevents the binding of Wnt to the low-density lipoprotein receptor-related protein (LRP) 5/6, downregulating Runx2 activity and OB differentiation (Baron \& Kneissel, 2013). Dickkopf-1 (Dkk-1) protein levels, produced by both MM and MM-BMSCs, are increased in MM patients with skeletal lesions (Fowler, Mundy, Lwin \& Edwards, 2012; Kaiser et al., 2008). Dkk-1 also promotes osteoclastogenesis and bone resorption by modulating RANKL and OPG expression in OBs (Spencer, Utting, Etheridge, Arnett \& Genever, 2006).

\section{Osteocytes}

OCYs represent $\sim 95 \%$ of bone cells and regulate the response of bone to mechanical stress. OCYs contribute to MBD by regulating both $\mathrm{OB}$ and $\mathrm{OC}$ activity through the secretion of factors including sclerostin, an inhibitor of the canonical Wnt $/ \beta$ catenin signalling (DelgadoCalle, Sato \& Bellido, 2017), and RANKL (Delgado-Calle, Bellido \& Roodman, 2014). Serum levels of sclerostin correlate with advanced MBD and poor patient survival (Terpos et al., 2012a). Recently, we and others reported that administration of neutralizing monoclonal anti-sclerostin antibodies, in preclinical model of MM, increases bone mass and reduces osteolytic lesions (Delgado-Calle et al., 2017; McDonald et al., 2017) and in combination with conventional anti-MM therapy such as carfilzomib, significantly reduces tumor burden (Eda et al., 2016). Physical interactions between MM cells and OCYs up-regulates

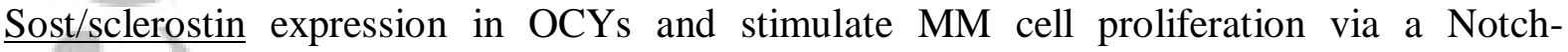
mediated pathway (Delgado-Calle et al., 2016), further contributing to the profound OB suppression.

\section{Osteoclasts}

MM cells directly stimulate OC formation by releasing pro-inflammatory osteoclastactivating factors (OAF), including RANKL, MIP-1 $\alpha$, TNF- $\alpha$, IL-3, IL-6, parathyroid hormone related protein $(\underline{\mathrm{PTHrP}})$ and hepatocyte growth factor $(\underline{\mathrm{HGF}})$. As a result of osteoclastic bone resorption, immobilized growth factors are released from the matrix, such 
as IGF-1, FGF and TGF- $\beta$ and promote MM cell growth, exacerbating the vicious cycle of MBD (reviewed in (Marino \& Roodman, 2017)). Moreover, we and others recently reported that OCs contribute to the increased MM-microvessel density via the production of MMderived VEGF and OC-derived osteopontin and MMP-9 contributing to disease progression (Giuliani, Storti, Bolzoni, Palma \& Bonomini, 2011). RANKL is the major regulator of both normal and pathological bone remodeling is mainly expressed and released by stromal cells, OBs and OCYs and is also secreted by activated T lymphocytes (Wada, Nakashima, Hiroshi \& Penninger, 2006). RANKL binds its receptor RANK, a member of the TNF receptor superfamily, expressed on the surface of OC precursors and mature OC, stimulating OC differentiation, survival and activity. OPG is the soluble decoy receptor for RANKL, produced by BMSCs and OCYs and blocks the interaction between RANKL and its receptor on OCs (Boyce \& Xing, 2008). An increased RANKL/OPG ratio in MM patients correlated with poor prognosis and reduced survival (Terpos et al., 2003). It is unclear however if MM cells directly produce RANKL or only induce its production by acting on cells in the bone microenvironment (Giuliani, Colla \& Rizzoli, 2004). In addition, OCY apoptosis induced by MM cells has recently been shown to contribute to MBD due to the release of osteocytic RANKL (Giuliani et al., 2012). Studies in preclinical models of MBD demonstrated that blocking RANKL, via administration of recombinant OPG or RANK-Fc, significantly decreased osteolytic lesions and tumor growth in mice.

MIP- $1 \alpha$ is a chemokine mainly produced by MM cells that enhances homing of MM cells to the marrow as well as their proliferation and adhesion to BMSCs cell. MIP-1 $\alpha$ acts as a chemotactic factor for monocytes and $\mathrm{OC}$ precursors directly inducing $\mathrm{OC}$ formation by binding to its receptor C-C chemokine receptor type 1 (CCR1) (Tsubaki et al., 2010) or by enhancing the activity of RANKL and IL-6 (Oyajobi et al., 2003). Recently, MIP-1 $\alpha$ was shown to directly impair OB mineralization via downregulation of osteocalcin expression and osterix modulation. Preclinical studies using the murine 5TGM1 model of MBD, showed that blocking CCR1 with the small molecule CCR1 antagonist, MLN3897 decreases tumor burden and bone destruction (Vallet et al., 2007) and partially reverses the inhibitory effects of MIP-1 $\alpha$ on OBs (Vallet et al., 2011). Small molecule CCR1 inhibitors are currently under development.

TNF- $\alpha$ produced by MM cells, MM-activated T cells and MM-BMSCs, enhances OC differentiation by stimulating a number of pro-survival signaling pathways including NF- $\mathrm{B}$, MAP-kinases and PI3K/Akt pathways and enhances the effects of RANKL (Boyce et al., 2005). Moreover, TNF- $\alpha$ induces expression of pro-survival genes in MM cells, promotes 
growth and confer chemotherapeutic resistance to apoptotic stimuli by activating several pathways, including both canonical and non-canonical NF-kB pathway (Li, Chen, Campbell, Bonavida \& Berenson, 2008). Furthermore, TNF- $\alpha$ increases the expression of VCAM1 and the secretion of RANKL and IL-6 by stromal cells (Teramachi et al., 2016), enhancing stromal cell support of osteoclastogenesis and MM cell growth and positively correlates with increased angiogenesis in MM patients (Bolkun et al., 2014).

IL-3 also affects osteoclastic bone resorption by cooperating with RANKL and MIP-1 $\alpha$ (Lee et al., 2004). IL-3 is produced by both MM cells and T cells in MM patients and its levels are elevated in the plasma of approximately $70 \%$ of MM patients. We reported that the mechanism of action of IL-3 in OCs, also involves Activin A produced by macrophages, and showed that activin A mediates the effects of IL-3 on osteoclastogenesis in vivo (Silbermann et al., 2014).

PTHrP is a secreted factor, functionally analogous to the parathyroid hormone (PTH), that controls a number of developmental, physiological and pathological processes (Rosen, 2013) and it is a major regulator of calcium homeostasis . PTHrP not only plays a key role in osteolytic metastases by solid tumors, but also enhances MM cell survival and reinforces MM-production of osteoclastogenic factors such as RANKL and monocyte chemoattractant protein-1 (MCP-1) (Cafforio et al., 2014). PTHrP induces the expression of the osteoblastic transcriptional repressor gene E4BP4, exacerbating MBD (Silvestris, Cafforio, De Matteo, Calvani, Frassanito \& Dammacco, 2008).

Semaphorin 4d ( $\underline{\text { Sema4D) }}$ also plays a role in MBD. It was recently reported that OCYs are the major source of Sema4D (Suvannasankha et al., 2016) along with MM cells and OCs (Terpos et al., 2012b). Sema4D increases OCs activity and suppresses of OBs differentiation and motility (Terpos et al., 2012b). A Sema4D antibody is currently in clinical trial for breast cancer bone metastasis (Patnaik et al., 2016).

\section{Adipocytes}

Bone marrow has a significant fat content and marrow adipocytes interact with MM cells, contributing to $\mathrm{MBD}$. The $\mathrm{C} / \mathrm{EBP} \alpha$ transcription factor and the master adipocyte regulator peroxisome proliferator-activated receptor $\gamma(\underline{\operatorname{PPAR} \gamma})$ regulate the differentiation of MSCs into adipocytes. The dynamic relationship and reciprocal repression between levels of marrow adipocytes and OBs is complex and is likely to play a functional role in both skeletal metastasis and MBD (Chen et al., 2016). Adipocytes serve as lipid reserves and may promote 
tumor growth and MBD by secreting specific endocrine signalling molecules, including adiponectin and growth factors (leptin, TNF $\alpha, \mathrm{MCP}-1$, and insulin) (reviewed in (McDonald, Fairfield, Falank \& Reagan, 2017)). Although a large prospective trial found no association between leptin levels and MM risk, instead, levels of adiponectin have been found to inversely correlate with MM pathogenesis suggesting that it may represent a novel therapeutic target in MBD (Fowler et al., 2011). Recently, Liu et al. demonstrated that MM cells reprogram adipocytes via increasing PPAR $\gamma^{\prime}$ methylation and altering adipokine production. These changes results in an enhanced osteoclastogenesis and suppression of osteoblastogenesis (Liu et al., 2019).

\section{Immune cells}

The immune cells that infiltrate tumors belong to adaptive immunity, characterized by antigen specificity and immunologic memory and innate immunity, typically lacking immunologic memory, with the exception of some subsets of natural killer (NK) cells. The tumor-immune interactions in MM represent a balance of pro- and anti-tumor interactions. All these types of immune cells have subsets that can mediate both pro- and antitumor effects and the balance between the two mediates an effective immune response in MM.

\section{T cells}

$\mathrm{T}$ cells arise from lymphoid stem cells and after maturation are characterized by the production and expression of antigen-specific, MHC-restricted receptor complexes (TCR/CD3) or subcomponents.

CD4/CD8 T-Cells: Cytotoxic CD8+ T cells (Th1/effector) mediate tumor protection, while regulatory CD4+ T cells (Th2/helper) can promote tumor growth (Dhodapkar, Borrello, Cohen \& Stadtmauer, 2017). In patients with monoclonal gammopathy of undetermined significance (MGUS), despite a significant tumor burden, the disease does not progress but subsists in a 'plateau phase'. This phenomenon is associated with the presence of expanded Tcell clones that have the immunophenotype of effector memory $\mathrm{T}$ cells $\left(\mathrm{CD} 3^{+} \mathrm{CD} 8^{+} \mathrm{CD} 57^{+}\right)$ and an improved survival (Brown et al., 2009). Identification of pre-malignancy-specific effector T cells in patients with MGUS represents an indirect evidence of host anti-tumor immune activity. Clonally expanded $\mathrm{T}$-cell populations have a much higher proliferative 
capacity in MM patients who have long-term survival than in MM patients with shorter survival (Dhodapkar, Krasovsky, Osman \& Geller, 2003).

\section{Th17}

Th17 cells are an important constituent of the adaptive immune response defined as proinflammatory CD4+ T helper cells that secrete the cytokine $\underline{\mathrm{IL}-17}$ and $\underline{\mathrm{IL}-22}$. IL-17 induces expression of a number of chemokines and cytokines including IL-6, TGF- $\beta$, granulocyte colony stimulating factor ( $\underline{\text { G-CSF}}$ ) or granulocyte-macrophage colony-stimulating factor (GM-CSF), matrix metalloproteinase (MMP), and ICAM-1 in a variety of cell types, including BMSC. TGF $\beta$ and IL-6, both expressed at high levels in MM bone marrow, influence the generation of Th17 cells and consequently modulate antitumor immune responses (Prabhala et al., 2010). A recent study found a significantly higher Th17 and lower Tregs in the long-term survival MM patients when compared with the MM group, indicating that promoting immune responses is therefore an important area of therapeutic intervention in MM (Bryant et al., 2013).

\section{Regulatory T(Tregs) cells}

CD4+Tregs cells secrete the inhibitory cytokines IL-10, required for their immune suppressive responses in vivo and TGF- $\beta$ involved in NK cells inhibition and T-cell suppression (Strauss, Bergmann, Szczepanski, Gooding, Johnson \& Whiteside, 2007), including those mounted by Th17 cells (Shen, Yuan, Liu \& Hu, 2012)

CD8+ Tregs have been identified as well but their mechanism of action involves TNF $\alpha$ and CCL4 instead of TGF- $\beta$ or IL-10, causing cells to become cytostatic (Muthu Raja et al., 2012).

and express high levels of cytotoxic T lymphocyte-associated antigen 4 (CTLA-4) and GITR. Tregs play an important role in the maintenance of self-tolerance and the modulation of overall immune responses against infections and tumor cells. In MM, abnormal Tregs may contribute to the myeloma-related immune dysfunction (Atanackovic et al., 2008).

\section{Natural Killer (NK) cells}

NK cells are lymphocytes defined as CD56+CD3- that function as cytotoxic cells in a nonHLA-restricted manner. Phenotypic studies showed that, NK cells from MM patients express programmed cell death protein 1 (PD-1), compared to healthy individuals, indicating that MM cells induce functional changes to the immune system in order to create an 
immunosuppressive environment favourable for its growth (Benson et al., 2010). NK cells also express a variety of surface receptors, including NKG2D that is critical for the recognition and lysis of MM cells (Talebian et al., 2014). Plasma cells, including MM cells, express MHC class I polypeptide-related sequence A (MICA) antigen that can shed and circulate as a soluble form (sMICA) in the plasma. MICA suppresses NK cells by binding to NKG2D. The MICA expression levels on plasma cells, as well as sMICA levels correlate with MM progression. MGUS patients express high levels of MICA on their plasma cells compared to normal donors and have high levels of anti-MICA antibodies, whereas MM patients express intermediate MICA levels but high sMICA levels and do not have antiMICA antibodies (Jinushi et al., 2008).

\section{Therapeutic targeting of multiple myeloma bone disease}

Novel treatments have improved patient's quality of life and overall survival although MM remains incurable. Bone-targeted therapy has become primarily important has the life expectancy of MM patients has significantly increased. MBD treatments are complex and aim mainly to reduce the development of new osteolytic lesion and prevent the onset of bone pain, spinal cord compression, pathological fracture and hyperalcemia. Moreover, recent studies have shown that restoring normal bone remodelling may synergise with conventional anti-MM therapies in reducing tumour proliferation and further preventing the development of new bone disease. Current MBD management utilizes a combination of chemotherapy, localized radiotherapy and surgery.

\subsection{Current Therapies}

\section{Antiresorptive}

\section{Bisphosphonates}

The standard care for the management of MBD are antiresorptive therapies, such us bisphosphonates (BPs) (Pozzi \& Raje, 2011). BPs are pyrophosphate analogues that inhibit farnesyl pyrophosphate synthases, the key regulatory enzyme in the mevalonate pathway. BPs therapies, initially used to prevent calcification of soft tissue, are used for the treatment of excessive bone resorption. BPs selectively binds and are adsorbed to mineral surfaces in bone and internalized by OCs during resorption inducing their apoptosis (Russell \& Rogers, 1999). 
BPs are classified into two groups with different modes of action and clinical effects: nonnitrogen-containing BPs, such as clodronate and etidronate, are metabolically accumulated as non-hydrolysable analogues of ATP (Frith, Monkkonen, Auriola, Monkkonen \& Rogers, 2001). The more potent, nitrogen-containing BPs, such as pamidronate, alendronate and zoledronic acid, are not metabolized and inhibit enzymes of the mevalonate pathway, preventing protein prenylation that cause loss of resorption activity and induction of OC apoptosis (Kavanagh et al., 2006). Oral clodronate, intravenous pamidronate and intravenous zoledronic acid are the commonly used bisphosphonates for treatment of MM-induced skeletal related events, and to reduce new osteolytic lesions, new pathological fractures and hypercalcemia (Anderson et al., 2018). BPs treatment also improves MM-patients' quality of life as it reduces bone pain and spinal cord compression (Gralow \& Tripathy, 2007). Results from the MRC Myeloma IX trial proved that zoledronic acid was more effective in reducing skeletal related events and mortality in newly diagnosticated patients with symptomatic MM compared to clodronate (Morgan et al., 2010). This study also demonstrates, as previously showed preclinically, that zoledronic acid reduced tumor burden. Although the mechanism of its anti-tumour effect is still not entirely clear, by inhibiting bone resorption BPS might render the bone environment less favourable to the growth and adhesion to mineralized surfaces of MM cells. Moreover, BPs alone or in combination with various chemotherapeutic agents including doxorubicin, paclitaxel and cyclophosphamide have a pro-apoptotic and anti-proliferative effect on MM cells and enhanced $\gamma \delta$ T-cell-mediated immunosurveillance (Modi \& Lentzsch, 2012).

The choice of zoledronic acid over pamidronate as first line treatment for MBD is due to its reduced infusion time and side effects although both are equally effective in reducing MBD as indicated by the International Myeloma Working Group (IMWG) (Terpos et al., 2013). In order to define the duration and frequency of intravenous administration of zoledronic acid, the Z-MARK study measured markers of bone turnover, such us urinary N-terminal telopeptide of type I collagen (uNTX) and serum C-terminal telopeptide of type I collagen (CTX), and pyridinoline cross-links (ICTP), concluding that MM-patients should be treated with less frequent dosing of zoledronic acid beyond 1-2 years to reduce the development of skeletal related events (Raje et al., 2016). The major complication associated with the therapy is osteonecrosis of the jaw (which can occur in $3.5 \%$ of the patients) that increase with the dose and length of the exposure (Van den Wyngaert, Huizing \& Vermorken, 2007). Furthermore, BPs-treated patients can develop acute or chronic renal dysfunction, as kidneys are responsible for $40 \%$ of BPs excretion (Pozzi \& Raje, 2011) and atypical femoral fractures 
due to the reduced bone strength following long-term suppression of bone turnover by antiresorptive agents.

\section{Denosumab}

Denosumab $\left(\mathrm{Xgeva}^{\circledR}\right)$ is a fully human monoclonal antibody that binds with high affinity to the membrane-bound and soluble form of RANKL and prevents its binding to RANK receptor on OC. Denosumab a highly specific as it binds only to RANKL and not to other member of TNF superfamily. Denosumab has been approved for the management of metastatic bone diseases associated with solid tumors (Yee \& Raje, 2012) and in patients with osteoporosis - and recently glucocorticoid-induced osteoporosis - for increasing bone density (Lewiecki, 2018). FDA recently approved denosumab for the prevention of skeletal related events in patients with newly diagnosed multiple myeloma as a result of the '482 Study (NCT01345019), an international, Phase III, randomized, double-blind, multicentre clinical trial in which denosumab was compared to zoledronic acid (Raje et al., 2018). This study showed that the overall survival rate was similar in patients treated with zoledronic acid compared to denosumab-treated patients. Denosumab reduced skeletal related events and its efficacy was non-inferior to zoledronic acid with respect to time to the first event. Furthermore, denosumab-treated patients showed significantly lower rates of renal adverse events. Infect, denosumab is not cleared by the kidneys and its use is not restricted in patients with renal insufficiency that represent $25-50 \%$ of patients with MM. A single-arm Phase II study of the use of Denosumab in MM patients with renal insufficiency is currently on going. Denosumab could represent an additional standard of care treatment for patients with MBD and would be recommended in patients resistant to bisphosphonate treatment. In postmenopausal women, clinical studies have shown that denosumab discontinuation results in a rebound in the risk of multiple vertebral fracture due to the rapid loss of its positive effects on bone mineral density (Tsourdi et al., 2017). However, specific recommendations on how to discontinue denosumab treatment are needed in MM patients as it has been licensed for continuous use.

\section{Proteasome Antagonists}

Proteasome inhibitors, such as bortezomib, and its analogues carfilzomib alone or in combination with steroids and immunomodulatory agents such as dexamethasone and lenalidomide, respectively, have potent anti-MM effects and represent standard of care in MM patients (Kouroukis, Baldassarre, Haynes, Imrie, Reece \& Cheung, 2014). Moreover, 
bortezomib also directly inhibits OC differentiation and bone resorption, increases osteoblastic bone formation and prevent OCYs apoptosis induced by MM cells (Accardi, Toscani, Bolzoni, Dalla Palma, Aversa \& Giuliani, 2015). Although the exact mechanism of action on $\mathrm{OB}$ differentiation has not being fully understood, a number of preclinical and clinical studies have suggested that bortezomib increases $O B$ differentiation by upregulating BMP2 production and Runx2 transcriptional activity and reducing OCYs production of sclerostin in patients with relapse/refractory MM (Accardi, Toscani, Bolzoni, Dalla Palma, Aversa \& Giuliani, 2015; Terpos et al., 2012a). Furthermore, studies reported that in responsive MM patients treated with bortezomib, serum level of Dkk-1, and marker of bone resorption and RANKL were significantly decreased while level of alkaline phosphates and bone formation markers were increased (Lund et al., 2010).

\section{Immunomodulatory Drugs (IMiDs)}

IMiDs such as thalidomide, a glutamic acid derivative, and its analogues lenalidomide, and pomalidomide, are a group of compounds that are often used as both forefront and maintenance therapy for MM (Lee \& Borrello, 2016). They target both tumor cells and the microenvironment. IMiDs modulate the host microenvironment mainly by co-stimulation of CD4+ and CD8+ T cells (LeBlanc et al., 2004), augmentation and activation of NK and NKT cells and suppression of Tregs (Quach et al., 2010). The anti-myeloma activity of IMiDs is mediated via and downregulation of adhesion molecules, anti-angiogenesis and antiinflammatory effects and modulation of cytokine production due to inhibition of TNF $\alpha$ production and activity.

The first generation IMiD, thalidomide, is associated with significant toxicity in older patients. Second generation of IMiD, lenalidomide is a more potent drug with fewer side effects than thalidomide and is commonly used in newly-diagnosed multiple myeloma, relapsed refractory myeloma and as maintenance therapy after autologous stem cell transplantation (ASCT). Pomalidomide, a third generation IMiD, is 10 times more potent than lenalidomide and has shown impressive results in relapsed MM patients and in those refractory to both lenalidomide and bortezomib (Baljevic \& Holstein, 2018).

IMiDs and MM-tumor microenvironment interactions.

$\mathrm{SDF}-1 \alpha$ is a chemokine produced within the BM, which is responsible for the initial homing of plasma cells to the BM by binding their C-X-C chemokine receptor type 4 (CXCR-4, CD184) (Hideshima et al., 2002). It also potentiates the adhesion of MM to BMSC by 
modulation of adhesion molecules such as very late antigen (VLA-4) and leukocyte functionassociated antigen (LFA-1) on plasma cells and VCAM-1 and ICAM-1 on BMSC. These interactions result in activation of $\mathrm{NF}-\mathrm{kB}$, which has a positive feedback loop on the upregulation of intracellular adhesion molecules (Hideshima, Chauhan, Schlossman, Richardson \& Anderson, 2001). On the other hand, NF-kB activates transcription of a multitude of cytokines such as VEGF, basic fibroblast growth factors ( $\beta$ FGF), TGF- $\beta$, TNF $\alpha$, IGF-1, IL-10 and IL-6, which all contribute to promote MM cells proliferation (Chauhan et al., 1996). IMiDs inhibit TNF $\alpha$ production by activated macrophages, therefore inhibit the interaction of the MM cells with BMSC by downregulating the adhesion molecules such as leukocyte function-associated antigen (LFA-1) and VLA-4 on MM cells and ICAM-1 and VCAM-1 on BMSC cells (Hideshima, Chauhan, Schlossman, Richardson \& Anderson, 2001). By disrupting the direct interaction between MM cells and BMSC, IMiDs reduces the pro-survival effects of IL-6, produced by BMSCs, thus reducing cellular adhesion-mediated drug resistance (Breitkreutz et al., 2008).

IMiDs have anti-angiogenic and anti-inflammatory properties.

Although all IMiDs have anti-angiogenic activity, thalidomide has predominant antiangiogenic activity whereas lenalidomide and pomalidomide have far superior immune enhancing effects. The anti-angiogenic effects, through inhibition of VEGF, are not due to an anti-proliferative mechanisms directed towards endothelial cells but rather to modulation of the chemotactic factors involved in endothelial cell migration (Dredge et al., 2002). Moreover, IMiDs-induced anti-angiogenesis mechanism involves downregulation of PI3K/Akt signaling pathway (Dredge et al., 2005). IMiDs have broad anti-inflammatory properties inhibiting several pro-inflammatory cytokines which also hold pro-myeloma properties. For example, thalidomide, lenalidomide and pomalidomide inhibit the expression of COX-2 enzyme by shortening the half-life of the mRNA. This results in a net reduction of pro-inflammatory prostaglandins PGE2 production in stimulated PBMCs (Payvandi et al., 2004). PGE2 promotes tumor angiogenesis and IL-6 production (Zhang, Abe, Matsushima, Nishimura, Nawata \& Muta, 2005), therefore these drugs exert a potential therapeutic role in MM. The potencies of the three different drugs varies greatly. For example, inhibition of TNF $\alpha$ with lenalidomide was 2000 -fold more potent then thalidomide and 20000-fold less potent then with pomalidomide.

\section{IMiDs have anti-osteoclastogenic properties}

It has been reported that IMiDs, such as lenalidomide and pomalidomide, inhibited OC development by affecting OC precursors' lineage commitment thalidomide almost 
completely abrogated RANKL-induced OC formation by downregulating the expression of PU.1, a major transcriptional factor for osteoclastogenesis (Anderson et al., 2006). Inhibition of bone resorption is associated with a reduction of the expression of cathepsin $\mathrm{K}$ and $\alpha \mathrm{V} \beta 3$ integrin in the OC. A recent study showed that lenalidomide decreased serum boneremodeling markers in patients with refractory and relapsed MM and blocks OC-derived secretion of growth and survival factors (MIP-1a, BAFF, APRIL) and RANKL secretion from BMSCs, indicating that this agent reduces MM burden and directly prevents osteoclastogenesis (Breitkreutz et al., 2008). IMiDs where not found to stimulate OBs. Bolomsky et. al. indicates that IMiD inhibited OB differentiation in a class-related manner by downregulation of major OB regulators (e.g., Runx2, distal-less homeobox 5, pleiotrophin) and concurrent induction of secreted inhibitors of $\mathrm{OB}$ formation (e.g. Dkk1, activin A, gremlin 1). These results emphasis the need for bone anabolic therapeutics in combination with IMDis in myeloma, to counteract the negative impact of prolonged IMiD exposure on bone metabolism (Bolomsky et al., 2014).

\subsection{Novel Therapies}

\section{Anabolic Therapies}

\section{Activin A- Antagonist}

Activin A, released by BMSC and OCs, is both an OCs agonist as it synergizes with RANKL and directly induces OC differentiation, as well as an OBs inhibitor (Alves, Eijken, Bezstarosti, Demmers \& van Leeuwen, 2013; Silbermann et al., 2014). Results from a Phase I study in postmenopausal women showed that Sotatercept (ACE-011), a soluble activin receptor antagonist, significantly reduced bone resorption marker CTX and tartrate-resistant acid phosphatase (TRACP-5b) and increased alkaline phosphatese, the bone-specific formation marker (Ruckle et al., 2009). Sotatercept is currently in a multicentre Phase II clinical trial in combination with lenalidomide and dexamethasone for patients with relapsed and refractory MM with osteolytic bone lesions (NCT01562405) (Yee et al., 2015). Preliminary data reported that Sotatercept inhibited MM cell growth, improve anaemia and increases bone mass.

\section{Dkk1 Antagonist}

Due to its key role in primarily mediate OBs suppression and indirectly enhances OC function in MM (Zhou, Meng, Song \& Claret, 2013), Dkk1 represent an attractive therapeutic target for MBD. Results from clinical studies showed a relationship between Dkk1 and MBD 
as it is highly produced by MM cells from patients with osteolytic lesions compared to patients with MGUS or healthy donor (Kaiser et al., 2008; McDonald et al., 2017). These studies suggested that Dkk1 can be targeted to stimulate bone formation. Strategies directed towards Dkk1 include neutralizing inhibitors of Wnt signaling, proteasome inhibitors and tumor-produced endothelin-1 (ET-1).

Preclinical studies showed that the anti-Dkk1 antibody BHQ880 increased OB differentiation, upregulated $\beta$-catenin levels and downregulated NF- $\kappa \mathrm{B}$ activity and reduced IL-6 secretion (Fulciniti et al., 2009; Heath et al., 2009) and reduced tumor growth (Pozzi et al., 2013).

BHQ880, has been tested in patients with MM, in combination with approved anti-MBD therapy such zoledronic acid. BHQ880 may increase trabecular bone formation and block osteoclastogenesis and be beneficial in patients with relapsed or refractory MM (Iyer et al., 2014). A phase II clinical trial in evaluating BHQ880 use in MM patients that present with renal insufficiently has been recently completed although the results are yet to be published (NCT01337752).

\section{Anti-sclerostin}

A number of studies have demonstrated that inhibition of sclerostin may be exploited in disease characterized by high bone catabolic rate such as osteoporosis (McClung, 2017).

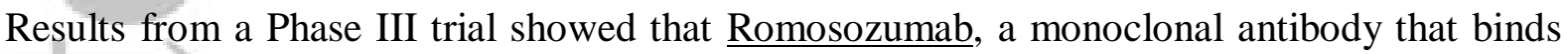
and neutralises sclerostin, increased bone formation, decreased bone resorption and reduced the risk of vertebral fractures in postmenopausal women with osteoporosis (Cosman et al., 2016). Furthermore, Romosozumab was superior to the aldronate and teriparatide, in increasing bone formation and reducing bone resorption. Elevated serum levels of sclerostin have been found in MM patients, which correlated with disease stage, marker of bone remodelling and number of pathological fractures (Wang et al., 2014). Preclinical studies conducted in our laboratory, combining Scl-Ab with available anti-MM drugs, such as bortezomib and dexamethasone, showed that Romosozumab did not negatively affect their anti-MM activity thus promoting its use in combinational therapy to improve bone disease and inhibit tumor progression in vitro (Delgado-Calle et al., 2017). Others reported a superior effect of Romosozumab combined with zoledronic acid in increasing bone volume and resistance to fracture in vivo (McDonald et al., 2017). These studies suggest that targeting sclerostin improve bone disease, can be efficiently combined with anti-MM drugs and antiresorptive agents and may be of value in MBD. Recently, the FDA approved 
Romosozumab for the treatment of osteoporosis in postmenopausal women with high fracture risk who are intolerant to other osteoporosis therapies. However, results from the ARCH study conducted by Amgen revealed that Romosozumab increased the risk of cardiovascular problems in patients compared to alendronate. These finding results in Amgen advising that Romosozumab should not be administered to patients who suffer myocardial infarction or stroke in the previous year.

\section{Bruton's tyrosine kinase (BTK)}

BTK is a non-receptor tyrosine kinase that plays a central role in the activation of downstream pathways associated with survival and proliferation of B cells (Petro \& Khan, 2001). MM.1R dexamethasone resistant cells presented an upregulated BTK expression at both protein and mRNA levels, suggesting a possible role of BTK in the mechanism of dexamethasone resistance (Chauhan et al., 2002). Ibrutinib is a first-in-class, potent, oncedaily, orally administered, covalently binding inhibitor of BTK. Selective inhibition of the BTK protein decreased MM-induced bone destruction by inhibiting osteoclastogenesis and suppressed tumor growth in an in vivo mouse model (Tai \& Anderson, 2012). BTK inhibition reduced in vivo homing of MM cells to bone in the SCID-rab model, inhibited MM cell growth and survival and altered their adhesion to BMSCs (Bam et al., 2013). Very recently, a Phase II trial, involving relapsed and refractory multiple myeloma patients, showed that Ibrutinib, with or without weekly dexamethasone, demonstrated promising activity and was well tolerated (Richardson et al., 2018).

\section{IL-6}

IL-6 is a pro-inflammatory cytokine recognized as a key molecule in the development of MM (Al-Hujaily, Oldham, Hari \& Medin, 2016). IL-6 is released by BM stem cells and binds to the IL-6 receptor (IL-6R) on myeloma cells stimulating their proliferation and survival (Burger, 2013) and promotes drug resistance. IL-6 is also produced by the MM cells, monocytes, endothelial cells, OBs and BM adipocytes and acts as a OC differentiation modulator, therefore is considered a cytokine that may be targetable for therapeutic purposes (Harmer, Falank \& Reagan, 2018).

$\underline{\text { Siltuximab }}$ a chimeric anti-IL-6 monoclonal antibody (mAb) (CNTO328) was tested in MM cell lines and in cells from refractory MM patients were it enhanced the cytotoxic effect of melphalan, dexamethasone, or bortezomib combined with dexamethasone (Hunsucker et al., 
2011). The phase I clinical trial had discouraging results, despite demonstrating the safety and tolerability of the drug, the efficacy of siltuximab was modest (Kurzrock et al., 2013). The phase II clinical trial, involving refractory or relapsed $\mathrm{MM}$ patients treated with siltuximab either alone or in combination with dexamethasone, reported an overall response rate of $17 \%$ in patients who received the combination therapy (Voorhees et al., 2013). Tocilizumab, a humanized anti-IL-6R mAb, is currently the subject of investigation in clinical cancer trials including MM (Matsuyama et al., 2011).

\section{Preclinical studies}

\section{Transforming Growth Factor Beta}

TGF- $\beta$ has been implicated in a number of cancers that metastasize to bone. As a consequence of the increased bone resorption, TGF- $\beta$ is released from the resorbed bone matrix and promotes MM cell growth. In bone, although the mechanism it still unclear, studies with genetically modified mice showed that TGF- $\beta$ affects OB differentiation via a mechanism that involve SMAD3 binding to Runx2 promoter, preventing its transcriptional activity and also promotes osteoclastogenesis and bone resorption (reviewed in (Juarez \& Guise, 2011)).

A number of recent studies have shown that a TGF- $\beta$ inhibitor neutralising antibody (1D11) alone or in combination with conventional therapies such as bortezomib and zoledronic acid inhibit OC activity and increase OB differentiation and bone formation without affecting tumour burden (Nyman et al., 2016; Paton-Hough et al., 2019). In another study however, a TGF- $\beta$ inhibitor, SRI31277 decreased MM tumour burden in vivo via a mechanism that involve Thrombospondin1 (TSP-1), a regulator of latent TGF- $\beta$ activation (Lu et al., 2016).

A humanized anti- TGF- $\beta$ antibody ( $(\mathrm{GC1008})$ is currently in clinical trials in breast cancer (NCT01401062) (Formenti et al., 2018).

\section{IL-17}

Th17 T cells are $\mathrm{T}$ lymphocytes, capable of producing the pro-inflammatory cytokine IL-17 but not interferon- $\gamma$ (IFN- $\gamma$ ) or IL-4, whose differentiation is mediated by TGF- $\beta$ and IL-6 (Zhou et al., 2007). In MM patients' BM, the ratio between CD4+/CD25+ population components is imbalanced with Tregs almost being absent and Th17 highly increased 
(Noonan, Marchionni, Anderson, Pardoll, Roodman \& Borrello, 2010). Moreover, it has been demonstrated that IL-17 release promotes MM cell growth (Prabhala et al., 2010) and induces OC activation as well as Th17 cell number correlates with the degree of lytic bone lesions (Noonan, Marchionni, Anderson, Pardoll, Roodman \& Borrello, 2010). A recent study showed that anti-IL-17A mAb (AIN457) significantly inhibited the growth of MM cell lines, as well as primary cells, and were able to overcome protective effects of BMSCs and significantly block in vitro OC differentiation (Prabhala et al., 2016). These data indicate Th17 as a potential drug target for the improvement of myeloma bone disease.

\section{CD26}

The OCs in the MM osteolytic lesions highly expresses CD26, a transmembrane glycoprotein with dipeptidyl peptidase IV (DPPIV) activity. A humanized anti-CD26 monoclonal antibody (HuCD26mAb) was able to impair human OC differentiation by modulating RANKsignalling pathway and inactivating downstream intracellular MKK3/6-p38MAPK pathway in OC precursor cells (Nishida et al., 2014). These results are encouraging foundation for using a bone-targeted therapy with anti-CD26 antibody in combination with systemic antiMM therapy to reduce the occurrence of total skeletal related events.

\section{miRNAs}

Micro RNAs (miRNAs) are short non coding RNAs of about 18-24 nucleotides length, that target the 3'-untranslated region (3'-UTR) of mRNAs and inhibiting protein translation (Bartel, 2004). Recent studies showed that miRNA dysregulation increases progressively from healthy individuals to MGUS and MM patients (Pichiorri et al., 2008), indicating that miRNA modulation can be involved in the transition from MGUS to MM, with specific signatures for MGUS and MM being determined (Roccaro et al., 2009).

Single dysregulated miRNAs may be directly involved in critical functions for malignant plasma cells such as cell cycle control, DNA repair and interactions with cell components of the microenvironment. Therefore, it is considered that up-regulated miRNAs are driving survival and expansion of plasma cells (oncomiRs), while down-regulated miRNAs are inhibitory signals for proliferation and progression (tumor suppressor miRNAs, TS-miRs). The pleiotropic effects of miRNAs make them very suitable tools for designing novel therapeutic strategies. For instance, miRNA enforced expression (mimics or antagomiRs) 
may be used against MM and its microenvironment (Rossi, Amodio, Di Martino, Caracciolo, Tagliaferri \& Tassone, 2013). Several miRs are downregulated in MM (e.g. miR-15, -16, 34, $-29 b,-125 b, 214,137-197,-145$ and -199). Their restoration by transfection of miR mimics within MM cells inhibited DNA synthesis, reduced proliferation and reduced the formation of tumoral driven new vasculature. Selective inhibition of the oncomiRs in MM (e.g. miR-21, 221/222, -125a) induced cell cycle arrest, impaired tumor cell proliferation and migration while promoting cell death (Rossi, Tagliaferri \& Tassone, 2015). Recent preclinical studies have investigated ways to restore the physiological state of the BM microenvironment, independently from direct activity against the MM by modulating miRNAs that affect cell components of the BM microenvironment.

MiR-29b replacement within OCLs inhibited bone resorption activity, even in the presence of MM cells, by decreasing OCL responsiveness to RANKL stimulation and decreased pro osteolytic enzymes levels (Rossi et al., 2013). Pitari and coworkers described that BMSCs up-regulate miR-21 in the presence of $\mathrm{MM}$ cells contributing to a tumor favouring microenvironment (Pitari et al., 2015). Moreover, miR-21 is a critical oncomiR in MM and its expression is strictly related to BM IL-6 levels. MiR-21 contributes to the suppression of OPG, therefore miR-21 antagonistic strategies revert OPG suppression and restored RANKL/OPG to physiological levels. Treatment with miR-202 mimics restored its level within MM-related BMSCs, therefore overcame growth-promoting activity of the BMSC (Shen et al., 2016).

\section{Concluding remarks}

Despite the recent improvements in MM treatment, more than $80 \%$ of MM patients suffer from skeletal disease and its related complications, implying that new treatment strategies are needed. The excessive osteoclastic bone resorption and persistent decrease in osteoblastic bone formation that cause dramatic bone loss, severe bone pain and pathological fractures, markedly decrease the quality of life of MM patients. A better understanding of the cellular and molecular mechanisms that tightly regulate the interplay between bone marrow cells and MM cells, has led to the discovery and introduction of a number of encouraging therapeutic agents. For the last two decades BPs have been the mainstream of treatment for MBD, but since January 2018, denosumab was approved for patients with active MM with compromised renal function. However, the major challenge in the treatment of MBD is to repair bone damage that results in healing of lytic bone lesions. The inability of the conventional $\mathrm{MM}$ chemotherapies to affect $\mathrm{OB}$ activity and induce bone formation 
demonstrate the need for the development of new safe and potent anabolic agents. Recent studies have shown that, proteasome inhibitors, in particular bortezomib, increase OB differentiation and may promote bone remineralization, independently from their anti-MM response. However, the extent, location, and patterns of bone mineralization vary among patients and are unpredictable.

Ongoing preclinical and clinical studies are evaluating the effect on bone remodelling of novel anti-MM agents, including proteasome inhibitor, ixazomib (NCT02499081), anti-CD38 antibody, daratumumab (NCT03475628) and Pim2 kinase inhibitors (NT01456689) in patients with relapsed and /or refractory MM. The ultimate goal of the management of MBD is not only reducing tumor burden but also restoring balanced of bone remodelling in order to prevent further bone loss and potentially repair bone damage in MM patients.

Nomenclature of Targets and Ligands:

Key protein targets and ligands in this article are hyperlinked to corresponding entries in http://www.guidetopharmacology.org, the common portal for data from the IUPHAR/BPS Guide to PHARMACOLOGY (Harding et al., 2018), and are permanently archived in the Concise Guide to PHARMACOLOGY 2017/18 (Alexander et al., 2017).

\section{Acknowledgments}

This work was supported by VA Merit Review Grant 5101CX000623-05 and NIH 5R01AR057308-09 (G.D.R.), Multiple Myeloma Research Foundation NID 125752 (S.M.) and ACS-IRG IRG-16-192-31 (D.N.P.).

\section{Conflicts of Interest}

G.D.R. is a consultant to Amgen. S.M. and D.N.P. have no conflict of interests regarding the publication of this paper. 


\section{References}

Accardi F, Toscani D, Bolzoni M, Dalla Palma B, Aversa F, \& Giuliani N (2015).

Mechanism of Action of Bortezomib and the New Proteasome Inhibitors on Myeloma Cells and the Bone Microenvironment: Impact on Myeloma-Induced Alterations of Bone Remodeling. Biomed Res Int 2015: 172458.

Adamik J, Galson DL, \& Roodman GD (2018). Osteoblast suppression in multiple myeloma bone disease. J Bone Oncol 13: 62-70.

Adamik J, Jin S, Sun Q, Zhang P, Weiss KR, Anderson JL, et al. (2017). EZH2 or HDAC1 Inhibition Reverses Multiple Myeloma-Induced Epigenetic Suppression of Osteoblast Differentiation. Mol Cancer Res 15: 405-417.

Adamik J, Silbermann R, Marino S, Sun Q, Anderson JL, Zhou D, et al. (2018). XRK3F2 Inhibition of p62-ZZ Domain Signaling Rescues Myeloma-Induced GFI1-Driven Epigenetic Repression of the Runx2 Gene in Pre-osteoblasts to Overcome Differentiation Suppression. Frontiers in Endocrinology 9.

Al-Hujaily EM, Oldham RA, Hari P, \& Medin JA (2016). Development of Novel Immunotherapies for Multiple Myeloma. Int J Mol Sci 17.

Alves RD, Eijken M, Bezstarosti K, Demmers JA, \& van Leeuwen JP (2013). Activin A suppresses osteoblast mineralization capacity by altering extracellular matrix (ECM) composition and impairing matrix vesicle (MV) production. Mol Cell Proteomics 12: 28902900. 
Anderson G, Gries M, Kurihara N, Honjo T, Anderson J, Donnenberg V, et al. (2006).

Thalidomide derivative CC-4047 inhibits osteoclast formation by down-regulation of PU.1.

Blood 107: 3098-3105.

Anderson K, Ismaila N, Flynn PJ, Halabi S, Jagannath S, Ogaily MS, et al. (2018). Role of

Bone-Modifying Agents in Multiple Myeloma: American Society of Clinical Oncology Clinical Practice Guideline Update. J Clin Oncol 36: 812-818.

Andrews SW, Kabrah S, May JE, Donaldson C, \& Morse HR (2013). Multiple myeloma: the bone marrow microenvironment and its relation to treatment. Br J Biomed Sci 70: 110-120.

Atanackovic D, Cao Y, Luetkens T, Panse J, Faltz C, Arfsten J, et al. (2008). $\mathrm{CD} 4+\mathrm{CD} 25+\mathrm{FOXP} 3+\mathrm{T}$ regulatory cells reconstitute and accumulate in the bone marrow of patients with multiple myeloma following allogeneic stem cell transplantation. Haematologica 93: 423-430.

Baljevic M, \& Holstein SA (2018). Present and Future of Immunotherapy in the Management of Multiple Myeloma. J Oncol Pract 14: 403-410.

Bam R, Ling W, Khan S, Pennisi A, Venkateshaiah SU, Li X, et al. (2013). Role of Bruton's tyrosine kinase in myeloma cell migration and induction of bone disease. Am J Hematol 88: 463-471.

Baron R, \& Kneissel M (2013). WNT signaling in bone homeostasis and disease: from human mutations to treatments. Nat Med 19: 179-192. 
Bartel DP (2004). MicroRNAs: genomics, biogenesis, mechanism, and function. Cell 116: 281-297.

Benson DM, Jr., Bakan CE, Mishra A, Hofmeister CC, Efebera Y, Becknell B, et al. (2010). The PD-1/PD-L1 axis modulates the natural killer cell versus multiple myeloma effect: a therapeutic target for CT-011, a novel monoclonal anti-PD-1 antibody. Blood 116: 22862294.

Bolkun L, Lemancewicz D, Jablonska E, Kulczynska A, Bolkun-Skornicka U, Kloczko J, et al. (2014). BAFF and APRIL as TNF superfamily molecules and angiogenesis parallel progression of human multiple myeloma. Ann Hematol 93: 635-644.

Bolomsky A, Schreder M, Meissner T, Hose D, Ludwig H, Pfeifer S, et al. (2014). Immunomodulatory drugs thalidomide and lenalidomide affect osteoblast differentiation of human bone marrow stromal cells in vitro. Exp Hematol 42: 516-525.

Boyce BF, Li P, Yao Z, Zhang Q, Badell IR, Schwarz EM, et al. (2005). TNF-alpha and pathologic bone resorption. Keio J Med 54: 127-131.

Boyce BF, \& Xing L (2008). Functions of RANKL/RANK/OPG in bone modeling and remodeling. ArchBiochemBiophys 473: 139-146.

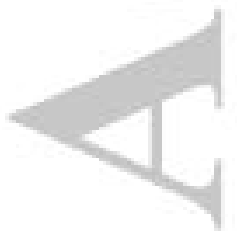


Breitkreutz I, Raab MS, Vallet S, Hideshima T, Raje N, Mitsiades C, et al. (2008). Lenalidomide inhibits osteoclastogenesis, survival factors and bone-remodeling markers in multiple myeloma. Leukemia 22: 1925-1932.

Brown RD, Spencer A, Ho PJ, Kennedy N, Kabani K, Yang S, et al. (2009). Prognostically significant cytotoxic $\mathrm{T}$ cell clones are stimulated after thalidomide therapy in patients with multiple myeloma. Leuk Lymphoma 50: 1860-1864.

Bryant C, Suen H, Brown R, Yang S, Favaloro J, Aklilu E, et al. (2013). Long-term survival in multiple myeloma is associated with a distinct immunological profile, which includes proliferative cytotoxic T-cell clones and a favourable Treg/Th17 balance. Blood Cancer J 3: e148.

Burger R (2013). Impact of interleukin-6 in hematological malignancies. Transfus Med Hemother 40: 336-343.

Cafforio P, Savonarola A, Stucci S, De Matteo M, Tucci M, Brunetti AE, et al. (2014). PTHrP produced by myeloma plasma cells regulates their survival and pro-osteoclast activity for bone disease progression. Journal of bone and mineral research : the official journal of the American Society for Bone and Mineral Research 29: 55-66.

Chauhan D, Auclair D, Robinson EK, Hideshima T, Li G, Podar K, et al. (2002). Identification of genes regulated by dexamethasone in multiple myeloma cells using oligonucleotide arrays. Oncogene 21: 1346-1358. 
Chauhan D, Uchiyama H, Akbarali Y, Urashima M, Yamamoto K, Libermann TA, et al. (1996). Multiple myeloma cell adhesion-induced interleukin-6 expression in bone marrow stromal cells involves activation of NF-kappa B. Blood 87: 1104-1112.

Chen Q, Shou P, Zheng C, Jiang M, Cao G, Yang Q, et al. (2016). Fate decision of mesenchymal stem cells: adipocytes or osteoblasts? Cell Death Differ 23: 1128-1139.

Cosman F, Crittenden DB, Adachi JD, Binkley N, Czerwinski E, Ferrari S, et al. (2016). Romosozumab Treatment in Postmenopausal Women with Osteoporosis. N Engl J Med 375: $1532-1543$.

D'Souza S, del Prete D, Jin S, Sun Q, Huston AJ, Kostov FE, et al. (2011). Gfi1 expressed in bone marrow stromal cells is a novel osteoblast suppressor in patients with multiple myeloma bone disease. Blood 118: 6871-6880.

Delgado-Calle J, Anderson J, Cregor MD, Condon KW, Kuhstoss SA, Plotkin LI, et al. (2017). Genetic deletion of Sost or pharmacological inhibition of sclerostin prevent multiple myeloma-induced bone disease without affecting tumor growth. Leukemia.

Delgado-Calle J, Anderson J, Cregor MD, Hiasa M, Chirgwin JM, Carlesso N, et al. (2016). Bidirectional Notch Signaling and Osteocyte-Derived Factors in the Bone Marrow Microenvironment Promote Tumor Cell Proliferation and Bone Destruction in Multiple Myeloma. Cancer Res 76: 1089-1100. 
Delgado-Calle J, Bellido T, \& Roodman GD (2014). Role of osteocytes in multiple myeloma bone disease. Curr Opin Support Palliat Care 8: 407-413.

Delgado-Calle J, Sato AY, \& Bellido T (2017). Role and mechanism of action of sclerostin in bone. Bone 96: 29-37.

Dhodapkar MV, Borrello I, Cohen AD, \& Stadtmauer EA (2017). Hematologic Malignancies: Plasma Cell Disorders. Am Soc Clin Oncol Educ Book 37: 561-568.

Dhodapkar MV, Krasovsky J, Osman K, \& Geller MD (2003). Vigorous premalignancyspecific effector $\mathrm{T}$ cell response in the bone marrow of patients with monoclonal gammopathy. J Exp Med 198: 1753-1757.

Dredge K, Horsfall R, Robinson SP, Zhang LH, Lu L, Tang Y, et al. (2005). Orally administered lenalidomide (CC-5013) is anti-angiogenic in vivo and inhibits endothelial cell migration and Akt phosphorylation in vitro. Microvasc Res 69: 56-63.

Dredge K, Marriott JB, Macdonald CD, Man HW, Chen R, Muller GW, et al. (2002). Novel thalidomide analogues display anti-angiogenic activity independently of immunomodulatory effects. Br J Cancer 87: 1166-1172.

Eda H, Santo L, Wein MN, Hu DZ, Cirstea DD, Nemani N, et al. (2016). Regulation of Sclerostin Expression in Multiple Myeloma by Dkk-1: A Potential Therapeutic Strategy for Myeloma Bone Disease. Journal of bone and mineral research : the official journal of the American Society for Bone and Mineral Research 31: 1225-1234. 
Formenti SC, Lee P, Adams S, Goldberg JD, Li X, Xie MW, et al. (2018). Focal Irradiation and Systemic TGFbeta Blockade in Metastatic Breast Cancer. Clinical cancer research : an official journal of the American Association for Cancer Research 24: 2493-2504.

Fowler JA, Lwin ST, Drake MT, Edwards JR, Kyle RA, Mundy GR, et al. (2011). Hostderived adiponectin is tumor-suppressive and a novel therapeutic target for multiple myeloma and the associated bone disease. Blood 118: 5872-5882.

Fowler JA, Mundy GR, Lwin ST, \& Edwards CM (2012). Bone marrow stromal cells create a permissive microenvironment for myeloma development: a new stromal role for Wnt inhibitor Dkk1. Cancer Res 72: 2183-2189.

Frith JC, Monkkonen J, Auriola S, Monkkonen H, \& Rogers MJ (2001). The molecular mechanism of action of the antiresorptive and antiinflammatory drug clodronate: evidence for the formation in vivo of a metabolite that inhibits bone resorption and causes osteoclast and macrophage apoptosis. Arthritis Rheum 44: 2201-2210.

Fulciniti M, Tassone P, Hideshima T, Vallet S, Nanjappa P, Ettenberg SA, et al. (2009). Anti-DKK1 mAb (BHQ880) as a potential therapeutic agent for multiple myeloma. Blood 114: $371-379$.

Garcia-Gomez A, Sanchez-Guijo F, Del Canizo MC, San Miguel JF, \& Garayoa M (2014). Multiple myeloma mesenchymal stromal cells: Contribution to myeloma bone disease and therapeutics. World J Stem Cells 6: 322-343. 
Ghali O, Chauveau C, Hardouin P, Broux O, \& Devedjian JC (2010). TNF-alpha's effects on proliferation and apoptosis in human mesenchymal stem cells depend on RUNX2 expression. Journal of bone and mineral research : the official journal of the American Society for Bone and Mineral Research 25: 1616-1626.

Giuliani N, Colla S, Morandi F, Lazzaretti M, Sala R, Bonomini S, et al. (2005). Myeloma cells block RUNX2/CBFA1 activity in human bone marrow osteoblast progenitors and inhibit osteoblast formation and differentiation. Blood 106: 2472-2483.

Giuliani N, Colla S, \& Rizzoli V (2004). New insight in the mechanism of osteoclast activation and formation in multiple myeloma: focus on the receptor activator of NF-kappaB ligand (RANKL). Exp Hematol 32: 685-691.

Giuliani N, Ferretti M, Bolzoni M, Storti P, Lazzaretti M, Dalla Palma B, et al. (2012). Increased osteocyte death in multiple myeloma patients: role in myeloma-induced osteoclast formation. Leukemia 26: 1391-1401.

Giuliani N, \& Rizzoli V (2007). Myeloma cells and bone marrow osteoblast interactions: role in the development of osteolytic lesions in multiple myeloma. Leuk Lymphoma 48: 23232329.

Giuliani N, Storti P, Bolzoni M, Palma BD, \& Bonomini S (2011). Angiogenesis and multiple myeloma. Cancer Microenviron 4: 325-337. 
Gralow J, \& Tripathy D (2007). Managing metastatic bone pain: the role of bisphosphonates. J Pain Symptom Manage 33: 462-472.

Guo W, Gao Y, Li N, Shao F, Wang C, Wang P, et al. (2017). Exosomes: New players in cancer (Review). Oncol Rep 38: 665-675.

Harding SD, Sharman JL, Faccenda E, Southan C, Pawson AJ, Ireland S, et al. (2018). The IUPHAR/BPS Guide to PHARMACOLOGY in 2018: updates and expansion to encompass the new guide to IMMUNOPHARMACOLOGY. Nucleic Acids Res 46: D1091-D1106.

Harmer D, Falank C, \& Reagan MR (2018). Interleukin-6 Interweaves the Bone Marrow Microenvironment, Bone Loss, and Multiple Myeloma. Front Endocrinol (Lausanne) 9: 788.

Heath DJ, Chantry AD, Buckle CH, Coulton L, Shaughnessy JD, Jr., Evans HR, et al. (2009). Inhibiting Dickkopf-1 (Dkk1) removes suppression of bone formation and prevents the development of osteolytic bone disease in multiple myeloma. Journal of bone and mineral research : the official journal of the American Society for Bone and Mineral Research 24: 425-436.

Hideshima T, Chauhan D, Hayashi T, Podar K, Akiyama M, Gupta D, et al. (2002). The biological sequelae of stromal cell-derived factor-1alpha in multiple myeloma. Mol Cancer Ther 1: 539-544. 
Hideshima T, Chauhan D, Schlossman R, Richardson P, \& Anderson KC (2001). The role of tumor necrosis factor alpha in the pathophysiology of human multiple myeloma: therapeutic applications. Oncogene 20: 4519-4527.

Hideshima T, Mitsiades C, Tonon G, Richardson PG, \& Anderson KC (2007). Understanding multiple myeloma pathogenesis in the bone marrow to identify new therapeutic targets. Nature reviews Cancer 7: 585-598.

Hu J, Van Valckenborgh E, Menu E, De Bruyne E, \& Vanderkerken K (2012). Understanding the hypoxic niche of multiple myeloma: therapeutic implications and contributions of mouse models. Dis Model Mech 5: 763-771.

Hunsucker SA, Magarotto V, Kuhn DJ, Kornblau SM, Wang M, Weber DM, et al. (2011). Blockade of interleukin-6 signalling with siltuximab enhances melphalan cytotoxicity in preclinical models of multiple myeloma. Br J Haematol 152: 579-592.

Iyer SP, Beck JT, Stewart AK, Shah J, Kelly KR, Isaacs R, et al. (2014). A Phase IB multicentre dose-determination study of BHQ880 in combination with anti-myeloma therapy and zoledronic acid in patients with relapsed or refractory multiple myeloma and prior skeletal-related events. Br J Haematol 167: 366-375.

Jinushi M, Vanneman M, Munshi NC, Tai YT, Prabhala RH, Ritz J, et al. (2008). MHC class I chain-related protein A antibodies and shedding are associated with the progression of multiple myeloma. Proc Natl Acad Sci U S A 105: 1285-1290. 
Juarez P, \& Guise TA (2011). TGF-beta in cancer and bone: implications for treatment of bone metastases. Bone 48: 23-29.

Kaiser M, Mieth M, Liebisch P, Oberlander R, Rademacher J, Jakob C, et al. (2008). Serum concentrations of DKK-1 correlate with the extent of bone disease in patients with multiple myeloma. Eur J Haematol 80: 490-494.

Kassen D, Moore S, Percy L, Herledan G, Bounds D, Rodriguez-Justo M, et al. (2014). The bone marrow stromal compartment in multiple myeloma patients retains capability for osteogenic differentiation in vitro: defining the stromal defect in myeloma. Br J Haematol 167: 194-206.

Kavanagh KL, Guo K, Dunford JE, Wu X, Knapp S, Ebetino FH, et al. (2006). The molecular mechanism of nitrogen-containing bisphosphonates as antiosteoporosis drugs. Proc Natl Acad Sci U S A 103: 7829-7834.

Kouroukis TC, Baldassarre FG, Haynes AE, Imrie K, Reece DE, \& Cheung MC (2014). Bortezomib in multiple myeloma: systematic review and clinical considerations. Curr Oncol 21: e573-603.

Kurzrock R, Voorhees PM, Casper C, Furman RR, Fayad L, Lonial S, et al. (2013). A phase I, open-label study of siltuximab, an anti-IL-6 monoclonal antibody, in patients with B-cell non-Hodgkin lymphoma, multiple myeloma, or Castleman disease. Clinical cancer research : an official journal of the American Association for Cancer Research 19: 3659-3670. 
LeBlanc R, Hideshima T, Catley LP, Shringarpure R, Burger R, Mitsiades N, et al. (2004). Immunomodulatory drug costimulates T cells via the B7-CD28 pathway. Blood 103: 17871790.

Lee JW, Chung HY, Ehrlich LA, Jelinek DF, Callander NS, Roodman GD, et al. (2004). IL-3 expression by myeloma cells increases both osteoclast formation and growth of myeloma cells. Blood 103: 2308-2315.

Lee SJ, \& Borrello I (2016). Role of the Immune Response in Disease Progression and Therapy in Multiple Myeloma. Cancer Treat Res 169: 207-225.

Lewiecki EM (2018). New and emerging concepts in the use of denosumab for the treatment of osteoporosis. Ther Adv Musculoskelet Dis 10: 209-223.

Li ZW, Chen H, Campbell RA, Bonavida B, \& Berenson JR (2008). NF-kappaB in the pathogenesis and treatment of multiple myeloma. Curr Opin Hematol 15: 391-399.

Lindner U, Kramer J, Rohwedel J, \& Schlenke P (2010). Mesenchymal Stem or Stromal Cells: Toward a Better Understanding of Their Biology? Transfus Med Hemother 37: 75-83.

Liu H, He J, Koh SP, Zhong Y, Liu Z, Wang Z, et al. (2019). Reprogrammed marrow adipocytes contribute to myeloma-induced bone disease. Sci Transl Med 11.

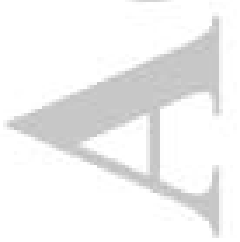


Lu A, Pallero MA, Lei W, Hong H, Yang Y, Suto MJ, et al. (2016). Inhibition of Transforming Growth Factor-beta Activation Diminishes Tumor Progression and Osteolytic Bone Disease in Mouse Models of Multiple Myeloma. Am J Pathol 186: 678-690.

Lund T, Soe K, Abildgaard N, Garnero P, Pedersen PT, Ormstrup T, et al. (2010). First-line treatment with bortezomib rapidly stimulates both osteoblast activity and bone matrix deposition in patients with multiple myeloma, and stimulates osteoblast proliferation and differentiation in vitro. Eur J Haematol 85: 290-299.

Marino S, \& Roodman GD (2017). Multiple Myeloma and Bone: The Fatal Interaction. Cold Spring Harb Perspect Med.

Matsumoto T, \& Abe M (2011). TGF-beta-related mechanisms of bone destruction in multiple myeloma. Bone 48: 129-134.

Matsuyama Y, Nagashima T, Honne K, Kamata Y, Iwamoto M, Okazaki H, et al. (2011). Successful treatment of a patient with rheumatoid arthritis and IgA-kappa multiple myeloma with tocilizumab. Intern Med 50: 639-642.

McClung MR (2017). Sclerostin antibodies in osteoporosis: latest evidence and therapeutic potential. Ther Adv Musculoskelet Dis 9: 263-270.

McDonald MM, Fairfield H, Falank C, \& Reagan MR (2017). Adipose, Bone, and Myeloma: Contributions from the Microenvironment. Calcif Tissue Int 100: 433-448. 
McDonald MM, Reagan MR, Youlten SE, Mohanty ST, Seckinger A, Terry RL, et al. (2017). Inhibiting the osteocyte specific protein sclerostin increases bone mass and fracture resistance in multiple myeloma. Blood.

Modi ND, \& Lentzsch S (2012). Bisphosphonates as antimyeloma drugs. Leukemia 26: 589594.

Morgan GJ, Davies FE, Gregory WM, Cocks K, Bell SE, Szubert AJ, et al. (2010). First-line treatment with zoledronic acid as compared with clodronic acid in multiple myeloma (MRC Myeloma IX): a randomised controlled trial. Lancet 376: 1989-1999.

Moschetta M, Mishima Y, Kawano Y, Manier S, Paiva B, Palomera L, et al. (2016). Targeting vasculogenesis to prevent progression in multiple myeloma. Leukemia 30: 11031115.

Munshi NC, \& Avet-Loiseau H (2011). Genomics in multiple myeloma. Clinical cancer research : an official journal of the American Association for Cancer Research 17: 12341242.

Muthu Raja KR, Kubiczkova L, Rihova L, Piskacek M, Vsianska P, Hezova R, et al. (2012). Functionally suppressive CD8 $\mathrm{T}$ regulatory cells are increased in patients with multiple myeloma: a cause for immune impairment. PloS one 7: e49446.

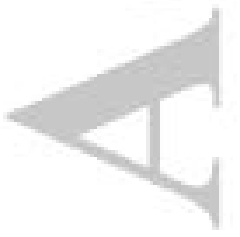


Nelson JB, Nguyen SH, Wu-Wong JR, Opgenorth TJ, Dixon DB, Chung LW, et al. (1999). New bone formation in an osteoblastic tumor model is increased by endothelin-1 overexpression and decreased by endothelin A receptor blockade. Urology 53: 1063-1069.

Nishida H, Suzuki H, Madokoro H, Hayashi M, Morimoto C, Sakamoto M, et al. (2014). Blockade of CD26 signaling inhibits human osteoclast development. Journal of bone and mineral research : the official journal of the American Society for Bone and Mineral Research 29: 2439-2455.

Noonan K, Marchionni L, Anderson J, Pardoll D, Roodman GD, \& Borrello I (2010). A novel role of IL-17-producing lymphocytes in mediating lytic bone disease in multiple myeloma. Blood 116: 3554-3563.

Nyman JS, Merkel AR, Uppuganti S, Nayak B, Rowland B, Makowski AJ, et al. (2016). Combined treatment with a transforming growth factor beta inhibitor (1D11) and bortezomib improves bone architecture in a mouse model of myeloma-induced bone disease. Bone 91: $81-91$.

Olechnowicz SW, \& Edwards CM (2014). Contributions of the host microenvironment to cancer-induced bone disease. Cancer Res 74: 1625-1631.

Oyajobi BO, Franchin G, Williams PJ, Pulkrabek D, Gupta A, Munoz S, et al. (2003). Dual effects of macrophage inflammatory protein-1alpha on osteolysis and tumor burden in the murine 5TGM1 model of myeloma bone disease. Blood 102: 311-319. 
Patnaik A, Weiss GJ, Leonard JE, Rasco DW, Sachdev JC, Fisher TL, et al. (2016). Safety, Pharmacokinetics, and Pharmacodynamics of a Humanized Anti-Semaphorin 4D Antibody, in a First-In-Human Study of Patients with Advanced Solid Tumors. Clinical cancer research : an official journal of the American Association for Cancer Research 22: 827-836.

Paton-Hough J, Tazzyman S, Evans H, Lath D, Down JM, Green AC, et al. (2019). Preventing and Repairing Myeloma Bone Disease by Combining Conventional Antiresorptive Treatment With a Bone Anabolic Agent in Murine Models. Journal of bone and mineral research : the official journal of the American Society for Bone and Mineral Research 34: 783-796.

Payvandi F, Wu L, Haley M, Schafer PH, Zhang LH, Chen RS, et al. (2004). Immunomodulatory drugs inhibit expression of cyclooxygenase-2 from TNF-alpha, IL-1beta, and LPS-stimulated human PBMC in a partially IL-10-dependent manner. Cell Immunol 230: $81-88$.

Petro JB, \& Khan WN (2001). Phospholipase C-gamma 2 couples Bruton's tyrosine kinase to the NF-kappaB signaling pathway in B lymphocytes. The Journal of biological chemistry 276: $1715-1719$.

Pichiorri F, Suh SS, Ladetto M, Kuehl M, Palumbo T, Drandi D, et al. (2008). MicroRNAs regulate critical genes associated with multiple myeloma pathogenesis. Proc Natl Acad Sci U S A 105: 12885-12890. 
Pitari MR, Rossi M, Amodio N, Botta C, Morelli E, Federico C, et al. (2015). Inhibition of miR-21 restores RANKL/OPG ratio in multiple myeloma-derived bone marrow stromal cells and impairs the resorbing activity of mature osteoclasts. Oncotarget 6: 27343-27358.

Pozzi S, Fulciniti M, Yan H, Vallet S, Eda H, Patel K, et al. (2013). In vivo and in vitro effects of a novel anti-Dkk1 neutralizing antibody in multiple myeloma. Bone 53: 487-496.

Pozzi S, \& Raje N (2011). The role of bisphosphonates in multiple myeloma: mechanisms, side effects, and the future. Oncologist 16: 651-662.

Prabhala RH, Fulciniti M, Pelluru D, Rashid N, Nigroiu A, Nanjappa P, et al. (2016). Targeting IL-17A in multiple myeloma: a potential novel therapeutic approach in myeloma. Leukemia 30: 379-389.

Prabhala RH, Pelluru D, Fulciniti M, Prabhala HK, Nanjappa P, Song W, et al. (2010). Elevated IL-17 produced by TH17 cells promotes myeloma cell growth and inhibits immune function in multiple myeloma. Blood 115: 5385-5392.

Quach H, Ritchie D, Stewart AK, Neeson P, Harrison S, Smyth MJ, et al. (2010). Mechanism of action of immunomodulatory drugs (IMiDS) in multiple myeloma. Leukemia 24: 22-32.

Raje N, Roodman GD, Willenbacher W, Shimizu K, Garcia-Sanz R, Terpos E, et al. (2018). A cost-effectiveness analysis of denosumab for the prevention of skeletal-related events in patients with multiple myeloma in the United States of America. J Med Econ 21: 525-536. 
Raje N, Vescio R, Montgomery CW, Badros A, Munshi N, Orlowski R, et al. (2016). Bone Marker-Directed Dosing of Zoledronic Acid for the Prevention of Skeletal Complications in Patients with Multiple Myeloma: Results of the Z-MARK Study. Clinical cancer research : an official journal of the American Association for Cancer Research 22: 1378-1384.

Ribatti D, Basile A, Ruggieri S, \& Vacca A (2014). Bone marrow vascular niche and the control of angiogenesis in multiple myeloma. Front Biosci (Landmark Ed) 19: 304-311.

Richardson PG, Bensinger WI, Huff CA, Costello CL, Lendvai N, Berdeja JG, et al. (2018). Ibrutinib alone or with dexamethasone for relapsed or relapsed and refractory multiple myeloma: phase 2 trial results. Br J Haematol 180: 821-830.

Roccaro AM, Sacco A, Thompson B, Leleu X, Azab AK, Azab F, et al. (2009). MicroRNAs 15a and 16 regulate tumor proliferation in multiple myeloma. Blood 113: 6669-6680.

Roodman GD (2009). Pathogenesis of myeloma bone disease. Leukemia 23: 435-441.

Roodman GD (2010). Pathogenesis of myeloma bone disease. J Cell Biochem 109: 283-291.

Roodman GD (2011). Osteoblast function in myeloma. Bone 48: 135-140.

Rosen CJ (2013) Primer on the metabolic bone diseases and disorders of mineral metabolism. vol. 8th ed. Ames, Iowa : Wiley-Blackwell, 2013. 
Rossi M, Amodio N, Di Martino MT, Caracciolo D, Tagliaferri P, \& Tassone P (2013). From target therapy to miRNA therapeutics of human multiple myeloma: theoretical and technological issues in the evolving scenario. Curr Drug Targets 14: 1144-1149.

Rossi M, Pitari MR, Amodio N, Di Martino MT, Conforti F, Leone E, et al. (2013). miR-29b negatively regulates human osteoclastic cell differentiation and function: implications for the treatment of multiple myeloma-related bone disease. J Cell Physiol 228: 1506-1515.

Rossi M, Tagliaferri P, \& Tassone P (2015). MicroRNAs in multiple myeloma and related bone disease. Ann Transl Med 3: 334.

Ruckle J, Jacobs M, Kramer W, Pearsall AE, Kumar R, Underwood KW, et al. (2009). Single-dose, randomized, double-blind, placebo-controlled study of ACE-011 (ActRIIAIgG1) in postmenopausal women. Journal of bone and mineral research : the official journal of the American Society for Bone and Mineral Research 24: 744-752.

Russell RG, \& Rogers MJ (1999). Bisphosphonates: from the laboratory to the clinic and back again. Bone 25: 97-106.

Saad F, Lipton A, Cook R, Chen YM, Smith M, \& Coleman R (2007). Pathologic fractures correlate with reduced survival in patients with malignant bone disease. Cancer 110: 18601867. 
Shen CJ, Yuan ZH, Liu YX, \& Hu GY (2012). Increased numbers of T helper 17 cells and the correlation with clinicopathological characteristics in multiple myeloma. J Int Med Res 40: $556-564$.

Shen X, Guo Y, Yu J, Qi J, Shi W, Wu X, et al. (2016). miRNA-202 in bone marrow stromal cells affects the growth and adhesion of multiple myeloma cells by regulating B cellactivating factor. Clin Exp Med 16: 307-316.

Siegel RL, Miller KD, \& Jemal A (2019). Cancer statistics, 2019. CA Cancer J Clin.

Silbermann R, Bolzoni M, Storti P, Guasco D, Bonomini S, Zhou D, et al. (2014). Bone marrow monocyte-/macrophage-derived activin A mediates the osteoclastogenic effect of IL3 in multiple myeloma. Leukemia 28: 951-954.

Silvestris F, Cafforio P, De Matteo M, Calvani N, Frassanito MA, \& Dammacco F (2008). Negative regulation of the osteoblast function in multiple myeloma through the repressor gene E4BP4 activated by malignant plasma cells. Clinical cancer research : an official journal of the American Association for Cancer Research 14: 6081-6091.

Spencer GJ, Utting JC, Etheridge SL, Arnett TR, \& Genever PG (2006). Wnt signalling in osteoblasts regulates expression of the receptor activator of NFkappaB ligand and inhibits osteoclastogenesis in vitro. J Cell Sci 119: 1283-1296.

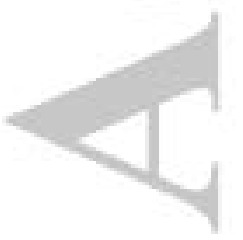


Storti P, Bolzoni M, Donofrio G, Airoldi I, Guasco D, Toscani D, et al. (2013). Hypoxiainducible factor (HIF)-1alpha suppression in myeloma cells blocks tumoral growth in vivo inhibiting angiogenesis and bone destruction. Leukemia 27: 1697-1706.

Strauss L, Bergmann C, Szczepanski M, Gooding W, Johnson JT, \& Whiteside TL (2007). A unique subset of CD4+CD25highFoxp3+ T cells secreting interleukin-10 and transforming growth factor-beta1 mediates suppression in the tumor microenvironment. Clinical cancer research : an official journal of the American Association for Cancer Research 13: 43454354

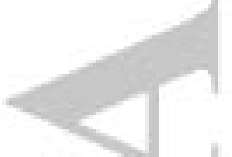

Suvannasankha A, Crean CD, Tompkins DR, Delgado-Calle J, Bellido TM, Roodman GD, et al. (2016). Regulation of Osteoblast Function in Myeloma Bone Disease By Semaphorin 4D. Blood 128: 4439.

Tai YT, \& Anderson KC (2012). Bruton's tyrosine kinase: oncotarget in myeloma. Oncotarget 3: 913-914.

Talebian L, Fischer DA, Wu J, Channon JY, Sentman CL, Ernstoff MS, et al. (2014). The natural killer-activating receptor, $\mathrm{NKG} 2 \mathrm{D}$, on $\mathrm{CD} 3+\mathrm{CD} 8+\mathrm{T}$ cells plays a critical role in identifying and killing autologous myeloma cells. Transfusion 54: 1515-1521.

Teramachi J, Silbermann R, Yang P, Zhao W, Mohammad KS, Guo J, et al. (2016). Blocking the $\mathrm{ZZ}$ domain of sequestosome1/p62 suppresses myeloma growth and osteoclast formation in vitro and induces dramatic bone formation in myeloma-bearing bones in vivo. Leukemia 30: 390-398. 
Terpos E, Christoulas D, Katodritou E, Bratengeier C, Gkotzamanidou M, Michalis E, et al. (2012a). Elevated circulating sclerostin correlates with advanced disease features and abnormal bone remodeling in symptomatic myeloma: reduction post-bortezomib monotherapy. Int J Cancer 131: 1466-1471.

Terpos E, Kastritis E, Bagratuni T, Christoulas D, Papatheodorou A, Kanellias N, et al. (2012b). Semaphorin-4D and Plexin-B1 Are Elevated in Multiple Myeloma Microenvironment and Possibly Contribute in the Development of Lytic Bone Disease. Blood 120: 1819 .

Terpos E, Morgan G, Dimopoulos MA, Drake MT, Lentzsch S, Raje N, et al. (2013). International Myeloma Working Group recommendations for the treatment of multiple myeloma-related bone disease. J Clin Oncol 31: 2347-2357.

Terpos E, Szydlo R, Apperley JF, Hatjiharissi E, Politou M, Meletis J, et al. (2003). Soluble receptor activator of nuclear factor kappaB ligand-osteoprotegerin ratio predicts survival in multiple myeloma: proposal for a novel prognostic index. Blood 102: 1064-1069.

Trotter TN, Gibson JT, Sherpa TL, Gowda PS, Peker D, \& Yang Y (2016). AdipocyteLineage Cells Support Growth and Dissemination of Multiple Myeloma in Bone. Am J Pathol 186: 3054-3063.

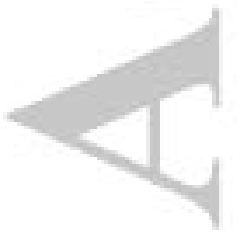


Tsourdi E, Langdahl B, Cohen-Solal M, Aubry-Rozier B, Eriksen EF, Guanabens N, et al. (2017). Discontinuation of Denosumab therapy for osteoporosis: A systematic review and position statement by ECTS. Bone 105: 11-17.

Tsubaki M, Kato C, Isono A, Kaneko J, Isozaki M, Satou T, et al. (2010). Macrophage inflammatory protein-1alpha induces osteoclast formation by activation of the MEK/ERK/cFos pathway and inhibition of the p38MAPK/IRF-3/IFN-beta pathway. J Cell Biochem 111: $1661-1672$

Vallet S, Mukherjee S, Vaghela N, Hideshima T, Fulciniti M, Pozzi S, et al. (2010). Activin A promotes multiple myeloma-induced osteolysis and is a promising target for myeloma bone disease. Proc Natl Acad Sci U S A 107: 5124-5129.

Vallet S, Pozzi S, Patel K, Vaghela N, Fulciniti MT, Veiby P, et al. (2011). A novel role for CCL3 (MIP-1alpha) in myeloma-induced bone disease via osteocalcin downregulation and inhibition of osteoblast function. Leukemia 25: 1174-1181.

Vallet S, Raje N, Ishitsuka K, Hideshima T, Podar K, Chhetri S, et al. (2007). MLN3897, a novel CCR1 inhibitor, impairs osteoclastogenesis and inhibits the interaction of multiple myeloma cells and osteoclasts. Blood 110: 3744-3752.

Van den Wyngaert T, Huizing MT, \& Vermorken JB (2007). Osteonecrosis of the jaw related to the use of bisphosphonates. Curr Opin Oncol 19: 315-322. 
Voorhees PM, Manges RF, Sonneveld P, Jagannath S, Somlo G, Krishnan A, et al. (2013). A phase 2 multicentre study of siltuximab, an anti-interleukin-6 monoclonal antibody, in patients with relapsed or refractory multiple myeloma. Br J Haematol 161: 357-366.

Wada T, Nakashima T, Hiroshi N, \& Penninger JM (2006). RANKL-RANK signaling in osteoclastogenesis and bone disease. Trends MolMed 12: 17-25.

Wang XT, He YC, Zhou SY, Jiang JZ, Huang YM, Liang YZ, et al. (2014). Bone marrow plasma macrophage inflammatory protein protein-1 alpha(MIP-1 alpha) and sclerostin in multiple myeloma: relationship with bone disease and clinical characteristics. Leuk Res 38: $525-531$.

Wang YG, Qu XH, Yang Y, Han XG, Wang L, Qiao H, et al. (2016). AMPK promotes osteogenesis and inhibits adipogenesis through AMPK-Gfi1-OPN axis. Cell Signal 28: 12701282.

Yee AJ, Laubach JP, Nooka AK, O'Donnell EK, Weller EA, Couture NR, et al. ( 2015). Phase 1 Dose-Escalation Study of Sotatercept (ACE-011) in Combination with Lenalidomide and Dexamethasone in Patients with Relapsed and/or Refractory Multiple Myeloma. American Society of Hematology.

Yee AJ, \& Raje NS (2012). Denosumab, a RANK ligand inhibitor, for the management of bone loss in cancer patients. Clin Interv Aging 7: 331-338. 
Zhang M, Abe Y, Matsushima T, Nishimura J, Nawata H, \& Muta K (2005). Selective cyclooxygenase 2 inhibitor NS-398 induces apoptosis in myeloma cells via a Bcl-2 independent pathway. Leuk Lymphoma 46: 425-433.

Zhou F, Meng S, Song H, \& Claret FX (2013). Dickkopf-1 is a key regulator of myeloma bone disease: opportunities and challenges for therapeutic intervention. Blood Rev 27: 261267.

Zhou L, Ivanov, II, Spolski R, Min R, Shenderov K, Egawa T, et al. (2007). IL-6 programs $\mathrm{T}(\mathrm{H})-17$ cell differentiation by promoting sequential engagement of the IL-21 and IL-23 pathways. Nature immunology 8: 967-974.

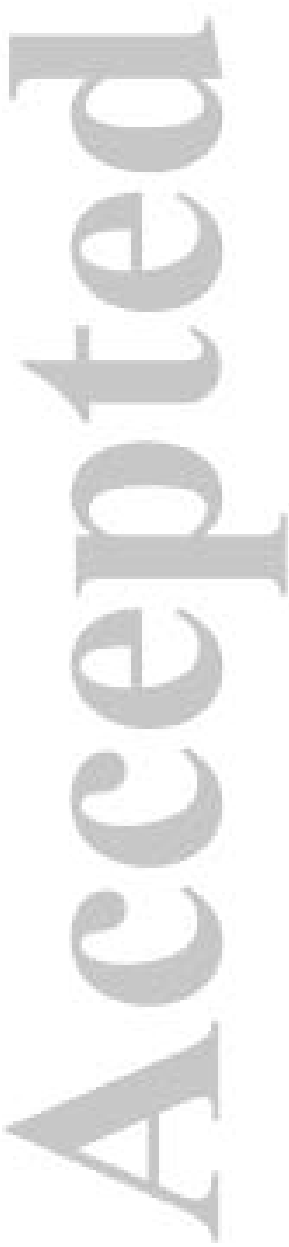




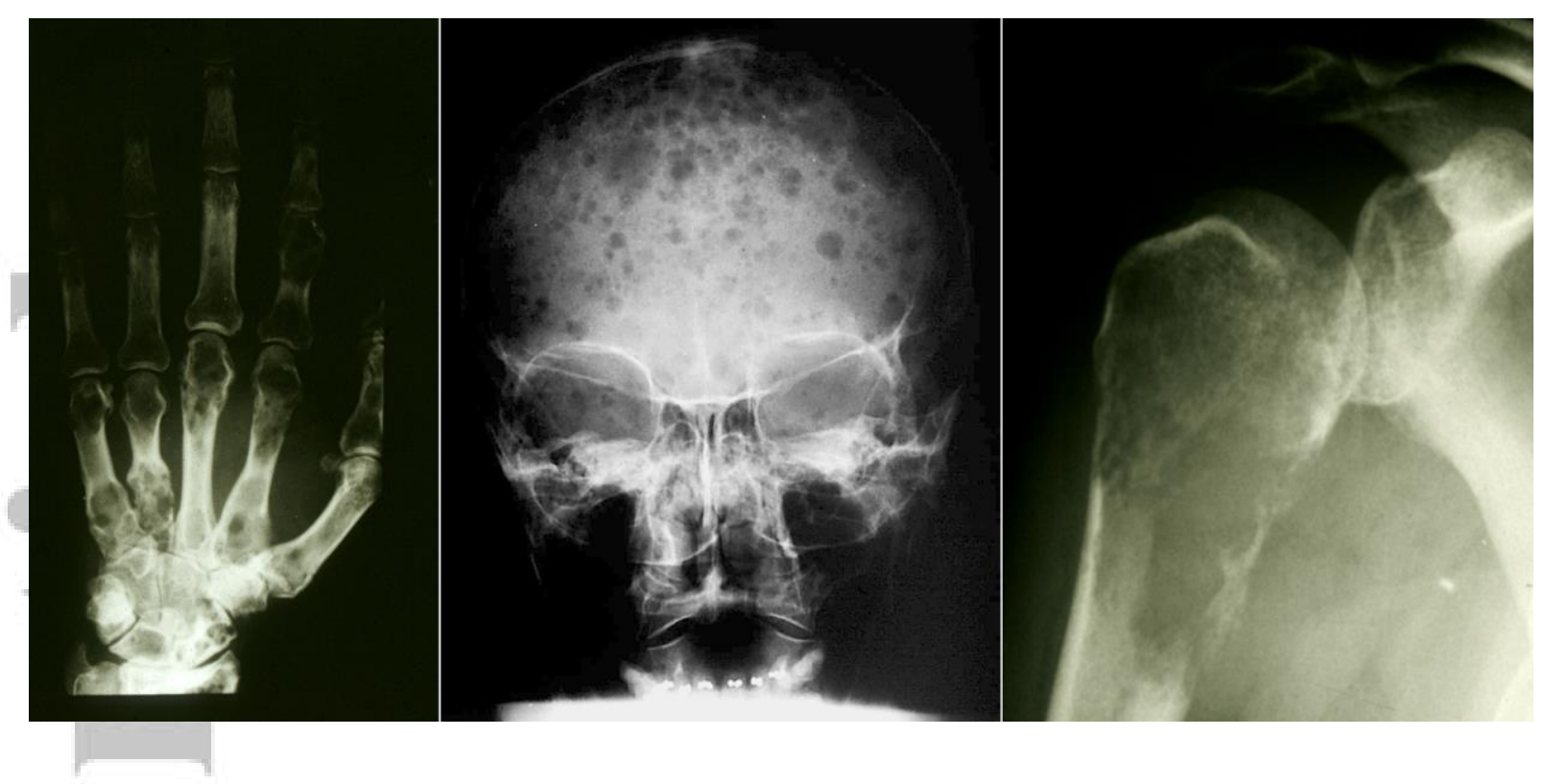

Fig 1: MBD can cause excessive bone destruction accompanied by absent new bone formation in any bone. Radiographic images of osteolytic lesions in the fingers (left panel), skull (middle panel) and shoulder (right panel) of myeloma patients (Courtesy of Dr. Mankin, Massachusetts General Hospital).

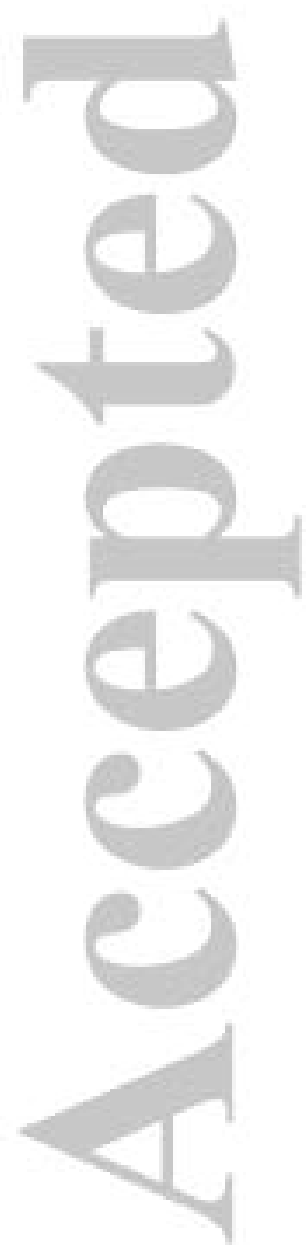




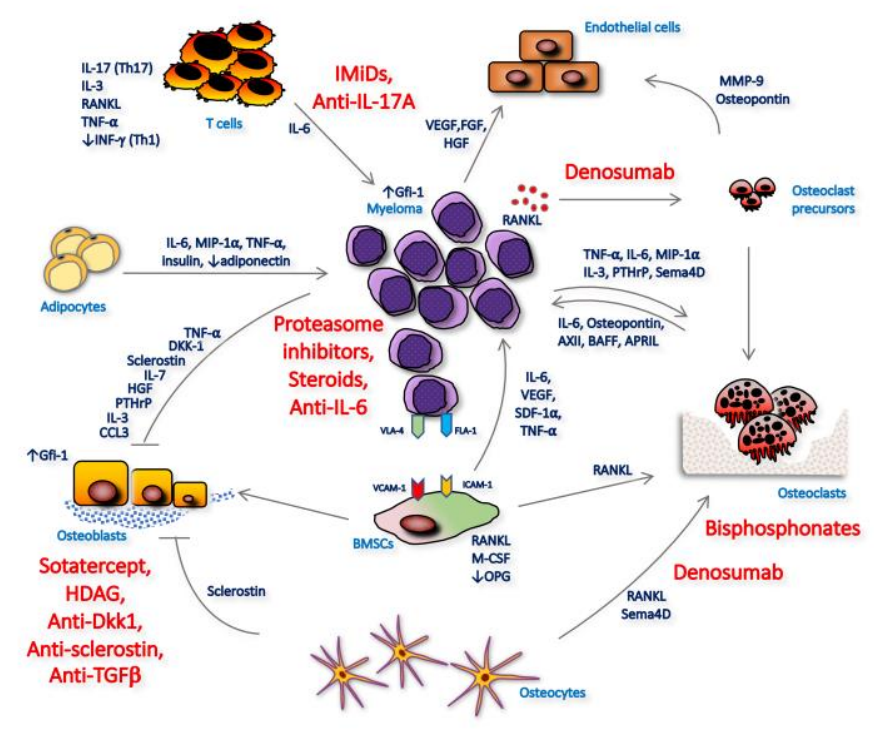

Fig 2: Cellular interactions and treatments of MBD. The excessive bone destruction and abnormal bone remodeling that characterizes MBD is the result of a complex interplay among the MM cells and the cells of the bone marrow microenvironment. MM cells stimulate osteoclast formation directly, through the production of several soluble factors (RANKL, MIP-1 $\alpha$, IL-3, and TNF- $\alpha$, Sema4D and PTHrP) or by physical interaction with marrow stromal cells and osteocyte, increasing their production of osteoclastogenic factors. The newly formed osteoclasts secrete soluble factors (osteopontin, MIP-1 $\alpha$, IL-6, AXII, BAFF, and APRIL) that stimulate tumor growth. Moreover, matrixassociated growth factors (TGF $\beta$, IGFs, FGF, PDGFs, and BMPs) are released from the resorbed bone and increase MM cells proliferation, exacerbating the osteolytic process. MM cells induce a profound suppression of bone formation by releasing osteoblast-inhibitory factors (DKK1, sclerostin, HGF, IL-7, and TNF- $\alpha$ ) and inducing the release of sclerostin from osteocytes and TNF- $\alpha$ from marrow stromal cells. Immune cells, adipocytes and endothelial cells also enhance MBD due to increase secretion of factors that affects both MM cells and bone cells. The development of new potent anabolic agents in combination with both antiresorptive and anti-tumour agents appear to be the most promising strategies for healing MBD. 